\title{
Not quite social - possible cases of gregarious behaviour of immatures of various lineages of Insecta in 100-million-year-old amber
}

\author{
Marie K. Hörnig, Carolin Haug, Patrick Müller \& Joachim T. Haug
}

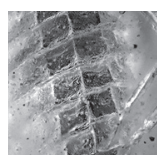

\begin{abstract}
The evolution of sociality in insects is a highly discussed topic in biology. Fossil findings are rarely included into the consideration, although they have a great potential to add also behavioural aspects to evolutionary reconstructions and can provide information about the minimum age of specific lifestyles in deep time. We briefly summarise concepts of reconstructing behaviour based on fossils and give a short overview of the concept of eusociality. The focus of this paper is the description of new findings of fossilised cases of aggregations in Cretaceous Myanmar amber. All specimens enclosed in these amber pieces are immatures. These findings come from four different lineages of Insecta: Neuroptera, Dermaptera, Orthoptera and Collembola. Some of these groups are usually not considered as typical examples for social interactions, but several grades of aggregation behaviour can be observed in all of these groups in different species living today. Active aggregation behaviour (or gregarious behaviour) can be seen as part and prerequisite of further social behaviour. Therefore, the investigation of this aspect can add new insights for a more comprehensive understanding of the evolution of complex strategies of social behaviour. - Key words: eusociality; sub-sociality; gregarism; fossilised behaviour; Cretaceous.
\end{abstract}

Hörnig, M.K., Haug, C., Müller, P. \& Haug, J.T. 2022. Not quite social - possible cases of gregarious behaviour of immatures of various lineages of Insecta in 100-million-year-old amber. Bulletin of Geosciences 97(1), 69-87 (5 figures). Czech Geological Survey, Prague. ISSN 1214-1119. Manuscript received September 4, 2020; accepted in revised form November 11, 2021; published online January 9, 2022; issued January 23, 2022.

Marie K. Hörnig, University of Greifswald, Zoological Institute and Museum, Cytology and Evolutionary Biology, Soldmannstr. 23, 17489 Greifswald, Germany • Carolin Haug \& Joachim T. Haug, Ludwig-Maximilians-Universität München (LMU Munich), Biocenter, Großhaderner Str. 2, 82152 Planegg-Martinsried, Germany \& GeoBio-Center at LMU, Richard-Wagner-Str. 10,80333 München, Germany; joachim.haug@palaeo-evo-devo.info • Patrick Müller, Kreuzbergstr. 90, 66482 Zweibrücken, Germany

\section{Reconstruction of behavioural aspects based on fossils}

The myriads of modern-day representatives of Euarthropoda, such as spiders, beetles, centipedes, lobsters and all their relatives, show an extremely wide range of different lifestyles and behavioural strategies. The evolution of these strategies, e.g. regarding feeding habits, reproduction, investment in offspring, sociality and many more, is a frequently treated subject in numerous studies. Most of them are naturally focussed on investigations of modern-day organisms (e.g. Tallamy 1984, Wilson \& Hölldobler 2005, Mas \& Kölliker 2008, Nowak et al. 2010).

The reconstruction of behaviour based on fossils for including these into evolutionary reconstructions is more challenging and only indirect, as direct observation is not possible. Yet, it still provides important additional data.

Indications of behavioural aspect in fossils seem to be relatively rarely preserved (e.g. Rust et al. 1999; Wedmann et al. 2007; Wappler et al. 2015; Wang et al. 2015, 2016;
Hsieh \& Plotnick 2020; Peris et al. 2020; further see below). However, there are several points which can be considered for a reconstruction of behavioural aspects based on fossils:

(1) Phylogenetic position: If a fossil can be identified to a specific ingroup in which all modern representatives possess a specific strategy or lifestyle (Witmer 1995), we can assume a similar lifestyle for the fossil. For example, if a fossil specimen can be identified as in-group representative of a group of which all modern forms are exclusively eusocial, we can infer that the fossil specimen was a representative of an also eusocial species. This approach has been summarised as the "extant phylogenetic bracket" concept of Witmer (1995; Boucot 1990: p. 5). However, the concept in the context of behavioural reconstruction allows only drawing rough conclusions as the fossil representative might not have yet evolved the specific specialisation, or it might have lost (secondarily) this feature. Also, for a reconstruction of evolutionary 
intermediate steps this approach is not applicable as it is only usable if there are no evolutionary changes in the strategies within the group. Yet, in combination with other points the phylogenetic position can provide the first hint for further investigations.

(2) Trace fossils: Trace fossils (ichnofossils) have been discussed extensively in different contexts in the literature, such as locomotion pattern or feeding traces (e.g. Bromley 1996, Miller 2007, Boucot \& Poinar Jr 2010). Also, for the reconstruction of raptorial behaviour, based e.g. on fossilised injuries of the prey, trace fossils can be useful (e.g. case of bitten trilobite from the Cambrian; Babcock 2003, Fatka et al. 2015). Relating to reproductive strategies, trace fossils could give some hints if in consequence of the behaviour distinct structures arise which can be preserved as fossils. This can be, e.g. case of insect nests (Cantil et al. 2018) or traces of oviposition (Béthoux et al. 2004, Pott et al. 2008, Sarzetti et al. 2009, Petrulevičius et al. 2011, Genise et al. 2017, summarised in $\mathrm{Na}$ et al. 2014).

The limitation for the usage of trace fossils for the reconstruction of behaviour is in many cases reduced to the question - Who caused the traces? If the causer is not preserved right next to the trace, it is hardly possible to identify the corresponding species, but maybe at least a larger group.

(3) "Frozen behaviour": The so-called "frozen behaviour" means cases of fossils, which are preserved in a specific moment, such as mating, oviposition (but most of these cases probably represent a stress-induced egg-laying), feeding, and others. One of the most famous examples is that of the "fighting dinosaurs" (Velociraptor and Protoceratops), which were first mentioned by KielanJaworowska \& Barsbold (1972). Cases of "frozen behaviour" within insects are especially known from amber inclusions (examples in Boucot 1990, Grimaldi 1996, Arillo 2007, Boucot \& Poinar Jr 2010, Gröhn 2015, Fischer \& Hörnig 2019, Hörnig et al. 2019). Amber is kind of predestined for these cases as the dying progress is that fast when the insects are trapped in the still viscid resin that they are often preserved in nearly life-like conditions (Arillo 2007).

(4) Functional morphology: Specific lifestyles and behavioural strategies are linked to several specific complex characters, so a specialized morphology can give hints for behavioural aspects. However, reconstructions of the evolution of behavioural aspects and lifestyles cannot completely be drawn by the consideration of only one morphological character but can be supported by several combinations of specific key features (for example, very simplified: specialised appendages for raptorial lifestyle). For interpretation of these structures, which might be linked to a specific lifestyle, in-depth knowledge of modern-day species is of advantage. This approach is following aspects of the actualism concept (summarised in Flemming 2004; examples in Haug, J.T. et al. 2012; Hörnig et al. 2018).

(5) Group fossilisation: Several fossils preserved closely to each other could be explained in the light of different interactions, for example: (a) male and female of the same species may have been fossilised while mating (e.g. Boucot \& Poinar Jr 2010, Gröhn 2015, Fischer \& Hörnig 2019 and discussion therein). Such cases demand the clear identification of the sex of the fossils. Such an explanation only works for finds of adults and cannot explain other cases, e.g. groups of immatures; (b) many individuals forming a swarm may have been fossilised together (e.g. Boucot \& Poinar Jr 2010; Haug, J.T. et al. 2013; Wang et al. 2014). In such cases we expect to find a certain structure concerning the developmental stages of the individuals (discussion in Haug, J.T. et al. 2013); (c) several individuals may have been feeding on a similar food source (e.g. Haug, J.T. et al. 2017) and then become fossilised together; (d) individuals have been living in a group that was actively held together and have been fossilised together (e.g. Fu et al. 2018). These can include species with different types of social behaviour, such as gregarism, sub-sociality, semi-sociality or eusociality.

\section{Sociality: eusocial insects}

The group Insecta is not only famous for being extraordinarily species-rich, but also for having various representatives that exhibit a so-called eusocial type of behaviour in today's living species, i.e. they live in colonies or insect societies. Among these colony-forming insects are astonishingly many representatives of ingroups of Hymenoptera. These include: (a) all species of ants (e.g. Hölldobler \& Wilson 1990); (b) many lineages of bees (Apidae), including species of sweat bees (Halictidae; more precisely species of Halictus Latreille, 1804 and Lasioglossum Curtis, 1833; e.g. Danforth et al. 2003, Gibbs et al. 2012), species of stingless bees (Meliponini; e.g. Schultz et al. 2001), all honey bees in the strict sense (Apis Linnaeus, 1758; e.g. Seeley 2009), species of orchid bees (Euglossini; Dressler 1982) and species of bumblebees (Bombus Latreille, 1802; e.g. Goulson 2003); (c) eusocial "true" wasps (Vespidae, e.g. Pickett \& Carpenter 2010), including all paper wasps (Polistinae) as well as hornets and yellow jackets (both representatives of Vespinae; (d) few species of Microstigmus Ducke, 1907 (e.g. Ross \& Matthews 1989), a group of digger wasps ("Crabronidae"). 
Besides the many species of eusocial hymenopterans there is one eusocial species of beetles (Austroplatypus incompertus Browne, 1971; Coleoptera; e.g. Smith et al. 2009), several eusocial species of aphids (Aphididae; e.g. Stern \& Foster 1996), few species of thrips (Thysanoptera; more specifically of the groups Kladothrips Froggatt, 1906 and Oncothrips Karny, 1911; e.g. Crespi 1992), and, more famous, all species of termites (Isoptera; e.g. Thorne 1997), factually eusocial cockroaches (Inward et al. 2007).

\section{The concept of eusociality}

Eusocial behaviour as a phenomenon has gained quite some attention over the recent decades. Already Darwin was puzzled by this very special type of cooperative behaviour, which seemed to be altruistic and was hence difficult to understand in his evolutionary framework. The ground-breaking thoughts of Hamilton and Maynard Smith with their kin-selection theory changed and finally resolved this issue. It properly anchored eusocial behaviour, as well as other types of social behaviour, in a well-formulated theoretical frame of evolutionary thinking. Since then, the phenomenon of eusociality has still received a lot of attention, leading to the fact that, unlike many other types of social interaction, eusociality is well delineated from a conceptual point of view, i.e. it can be recognised based on a set of several distinct features, generally summarised under three major criteria:

(1) Division of labour. Some individuals (or only one individual) within a group of organisms living together reproduce ("queens"), some do not ("workers, soldiers"). This is also referred to as the formation of castes. Castes can usually be recognised not only by differentiation of behaviour, but additionally by differences in morphology, leading for example to a distinct soldier morph, at least in many of the more highly derived eusocial species.

(2) Generations overlap. More specifically, the offspring generations overlap within the group, i.e. there are at least two generations of offspring, unlike in sub-social species in which there is often only one generation of offspring at a time.

(3) Cooperative care for not-direct offspring. This is usually coupled to the aspect before, meaning that one generation of offspring cares for the next. In less highly specialised forms of eusociality (often unfortunately termed "primitive eusocial") this might also refer to a part of the system in which several reproductive individuals are present, and these care for the offspring also of other individuals.

\section{The concept of eusociality, expanded}

Besides the often-cited three major aspects (outlined right above), additional phenomena seem to be related to eusociality. These can be either understood as a direct consequence ("effect") of living in a eusocial group or representing possible pre-adaptations ("cause"). These phenomena include:

(4) Unusually high relatedness of the offspring. This seems to be a major factor in all eusocial forms. Apparently, this high degree of relatedness may be caused by different mechanisms: (a) it may be caused by a haplo-diploidy sex determination mode as in Hymenoptera, i.e. females are diploid while males hatch from unfertilised eggs and are haploid. This leads to an asymmetric scheme of relatedness, with sisters being closer related among each other than they would be with their own offspring; (b) all individuals might represent clones as in Aphididae; in such a system it becomes meaningless if the one individual cannot reproduce as it will be genetically identical to all offspring in any case; (c) all individuals may show a high degree of inbreeding as in Isoptera and Thysanoptera. Comparable to the case of clones, this leads to a high degree of genetic similarity. As a remark: Thysanopterans are interesting in this aspect as they are similar to hymenopterans in using haplo-diploidy for sex determination, yet as inbreeding is present, they have male workers/soldiers, which is unknown in hymenopterans.

(5) A limited availability of a nest or cost-intense nest. If building a nest or defending it is especially cost-intense it appears to be highly beneficial to do so in a group. Also, if an existing structure will be used as a nest but its availability is strongly limited, it seems to be of advantage to share this nest. Yet, this aspect is coupled to the next point.

(6) Presence of structures of the individuals that can be used in group defence actions. This is related to the aspect of cooperatively defending a highly valuable nest ("fortress defence") against competitors. Sometimes such structures are either only present or especially hypertrophied in the soldier morphs. Such defending structures include: (a) a venom sting as in aculeatan hymenopterans. Although most ants do no longer possess such a sting, representatives of early branching off lineages within ants retain such a sting. It appears to be substituted by other types of chemical defence in more derived lineages of ants; (b) spiny, partly enlarged front legs as in representatives of Aphididae and Thysanoptera; (c) enlarged mandibles as present in representatives of Isoptera, but also some representatives of Hymenoptera.

As to be expected, there are additional representatives 
of the species-rich group Insecta that do not exhibit all of these characters, but only some or a single of these.

The various types of sociality within Euarthropoda, which do not fulfil the criteria of eusociality, are distinctly less represented in the literature. This is also reflected by inconsistent use of terminology of these types, such as sub-, semi-, or quasi-social and several synonymous terms, which might be misleading (Costa 2018). All these named terms are at least associated with the presence of parental or cooperative brood care (e.g. Eickwort 1981, Tallamy \& Wood 1986, Costa 2018).

However, also other types which do not include brood care, including communal or gregarious behaviour of nymphs/larvae with or without adults (see above), represent types of different grades of social behaviour. Aggregation behaviour, or gregarism, of young and/or adults is quite common in modern day forms of Euarthropoda, for example within Insecta, such as Blattodea (cockroaches), Dermaptera (ear wigs), Auchenorrhyncha (tree hoppers and relatives) and Coleoptera (beetles; Pitman \& Vité 1969, Sauphanor \& Sureau 1993, Harari et al. 1994, Bell et al. 2007, Santiago-Blay et al. 2012, Camacho et al. 2014). Living in such groups can have several advantages for the individuals: better food availability for young, protection against predators or inconvenient environmental factors (e.g. dryness) (e.g. Bell et al. 2007 for Blattodea). This behavioural mode can be seen as pre-requisite for the evolutionary development of further social and eusocial lifestyles.

\section{The evolution of eusociality and the fossil record}

Species with different types of social behaviour are of critical interest for understanding which selective pressures shaped the evolution of eusociality. This is related to the fact that it is unlikely that all features characterising eusociality evolved at once ("in one go"). More likely, these characters evolved in a stepwise manner. Hence, we should expect that ancestors of lineages with eusocial forms exhibited sub-social or semi-social behaviour.

The fossil record is a major source of information for many aspects of evolutionary reconstructions. Fossils may provide minimum ages for inferring the age of certain evolutionary lineages. Also, morphological specialisations can be recognised in a fossil, providing minimum ages for the presence of certain characters (different from inferring the age of lineages; $c f$. Haug, J.T. \& Haug, C. 2017). As stated above, more rarely the fossil record also provides clues about behavioural aspects of a once-living species (e.g. Rust et al. 1999; Wedmann et al. 2007; Haug, J.T. et al. 2012; Wappler et al. 2015; Wang et al. 2015, 2016; Barden \& Grimaldi 2016; Hörnig et al. 2017, 2018, and references above).
Recognising types of sociality in fossils is quite challenging (see discussion in Hörnig et al. 2016). Yet, one aspect of fossils is especially interesting in this aspect: the occurrence of several individuals of the same species at the same spot leading to a fossil preservation of several individuals in close proximity, as indeed certain findings could represent cases in which groups of social (sub-, semi-social or gregarious) insects have become fossilised together. Aggregations of fossil forms of Euarthropoda, which might have resulted from active gregarious behaviour, have been rarely described in the literature (e.g. Paterson et al. 2008, Engel 2009, Hörnig et al. 2016). However, only based on the case of a fossilisation of a group of individuals, it cannot clearly be concluded that this species showed a kind of social behaviour (e.g. discussion in Haug, J.T. et al. 2017), therefore it is crucial considering other possible interpretations (see above) and an extensive comparison to extant species.

Amber has an especially large potential to provide instances in which several individuals can be found together and provide enough details of the individuals to properly evaluate the case.

We report here several examples of cases in which conspecific individuals have become trapped together in 100-million-year-old Myanmar amber (also called Burmese amber). All cases represent groups of immatures. We discuss how far these fossils could represent indications of social behaviour in these species.

\section{Material and Methods}

Material. - In total, five pieces of amber were studied in detail. All specimens were collected in the Hukawng Valley, Kachin State, Myanmar. One amber piece was legally purchased on ebay.com from the trader burmite-researcher. It is now part of the collection of the Palaeo-Evo-Devo (PED) Research Group, Ludwig-Maximilians-Universität München (LMU Munich), Germany (registered collection, see Evenhuis 2021), under repository number PED 0083. The amber piece was not further processed after purchase. Four other pieces are part of the collection of one of the authors (PM) under repository numbers BUB 3150, 3162, 3193, and 3391. The raw amber pieces were first cut with a Dremel 3000. Afterwards they were polished with wet sandpaper, first grade 200 and then subsequently grade 600,1000 and 5000. The final polishing was performed with Sidol metal polish. All specimens are available for further study on request.

Methods. - The specimens were documented with composite imaging under different white light conditions, one specimen additionally with autofluorescence. The white-light microscopic images were recorded with 


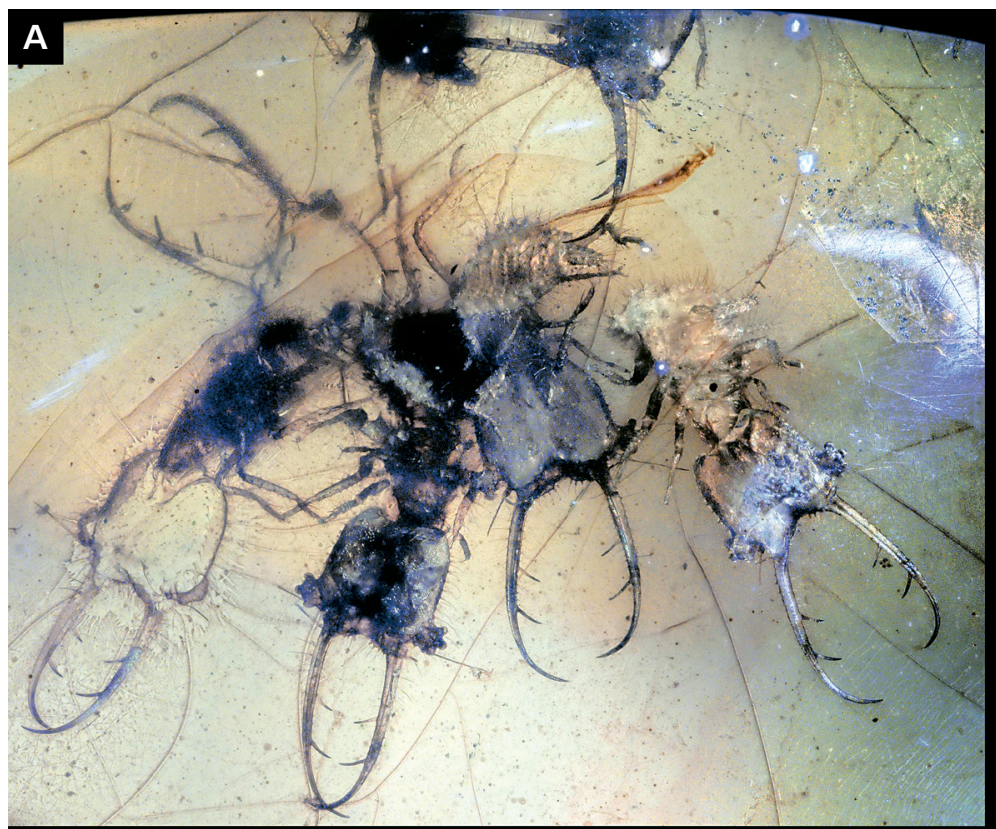

D
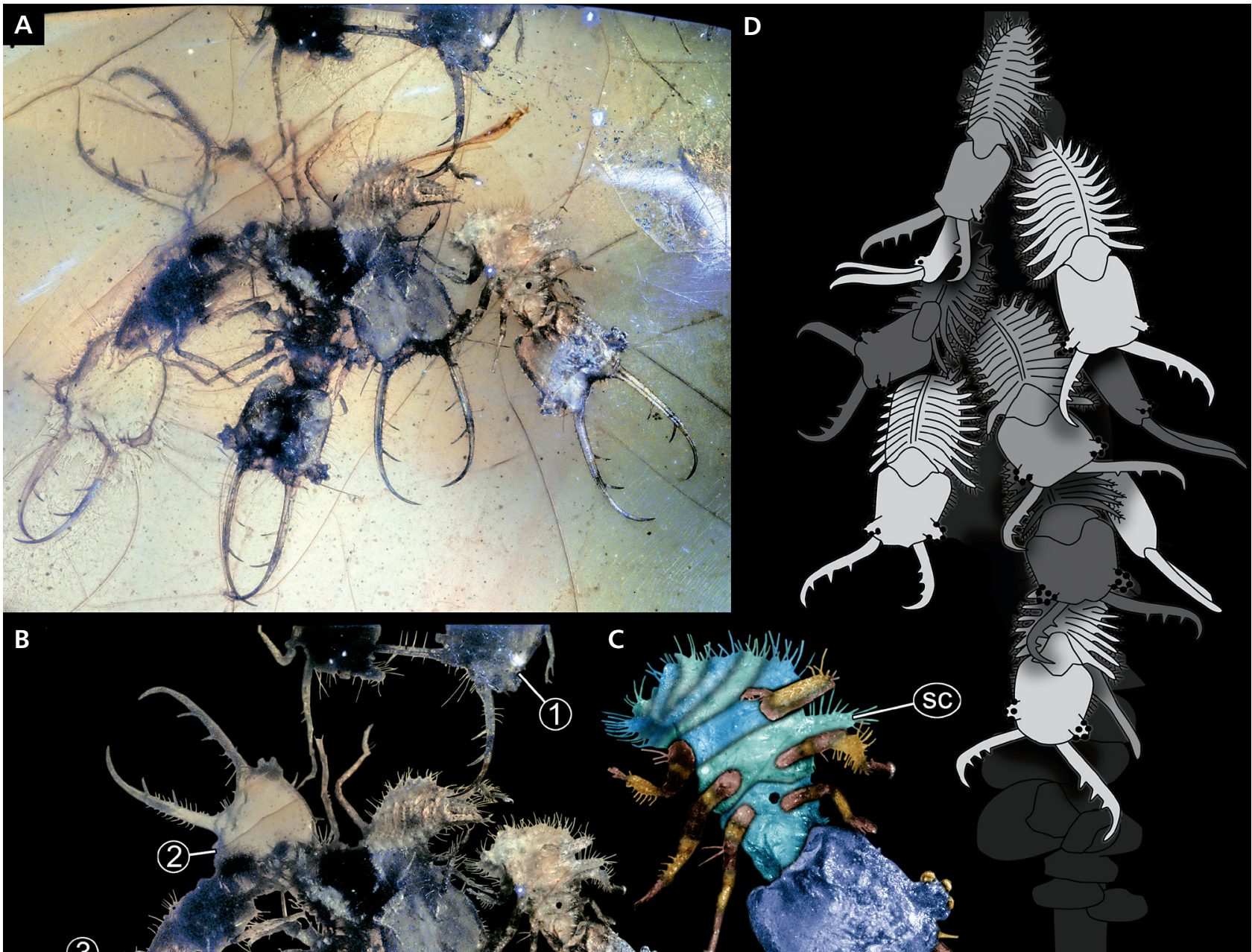

(2)-

(3)
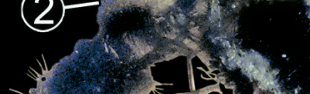

3)
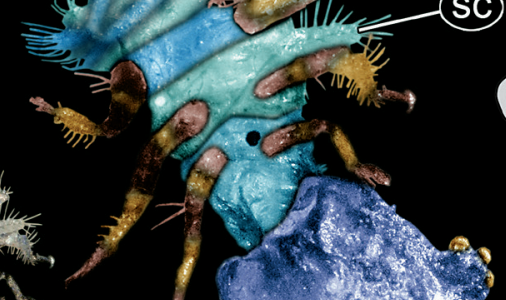

1.
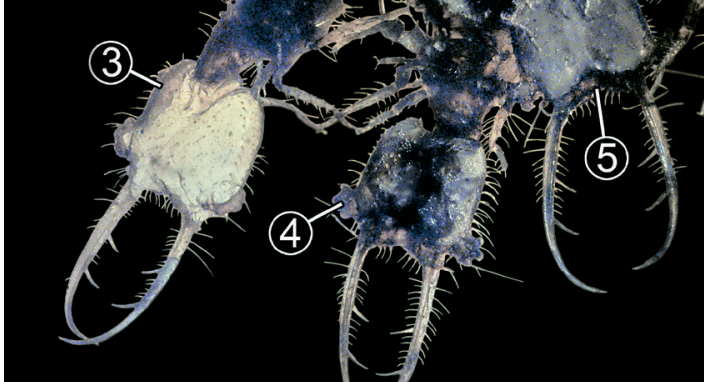

$1 \mathrm{~mm}$
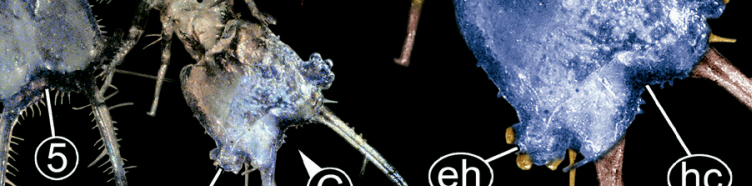

(6)
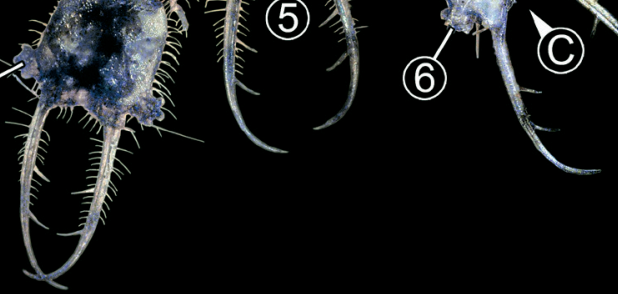

(eh)

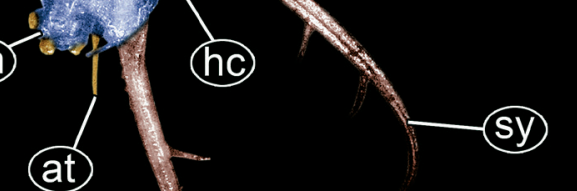

Figure 1. Amber piece with at least six owlfly-like larvae (repository number PED 0083). A - composite image of the group of animals. B - same as in A, but background manually removed to allow an easier recognition. C - colour-marked version of one of the specimens in B (specimen 6). D - simplified depiction of group defence in modern-day owlfly larvae (modified after Henry 1972). Abbreviations: 1-6 - number of specimen; at - antenna; eh - eye hill; hc - head capsule; sc - scolus; sy - stylet.

a Keyence VHX-6000 (as in Haug, J.T. et al. 2018) equipped with a 20-2000x objective, either under ring illumination or under coaxial cross-polarised illumination. Black and white background colour was used. To achieve an optimal result, every image was recorded with different exposure times (HDR; Haug, C. et al. 2013). For autofluorescence images, a Keyence BZ-9000 was used (see Haug, J.T. et al. 2011 for autofluorescence imaging).
Each image detail was documented as a stack, with the single images of the stack (frames) being recorded in different focal levels on z-axis to overcome limitations in depth of field. The frames of each stack were fused to achieve an entirely sharp image detail. Several adjacent stacks were recorded in $\mathrm{x}-\mathrm{y}$-axis to overcome limitations in the field of view. All image details were stitched to a final panorama image (e.g. Haug, J.T. et al. 2008; Kerp \& Bomfleur 2011). 


\section{Results}

\section{Neuropteran larvae, pieces 1 and 2}

Amber piece 1 (repository number PED 0083; Fig. 1) contains five complete larval representatives of Neuroptera, as well as an anterior body and part of a trunk; these may either belong to one individual or even to two. The minimum assumption is that there are six neuropteran larvae in this piece of amber. The larvae in amber piece 1 are equal in size, with an entire body length of about $2 \mathrm{~mm}$ (without appendages). Amber piece 2 (repository number BUB 3391; Fig. 2) contains three representatives of Insecta, a small beetle and two larval representatives of Neuroptera. Also, the neuropteran larvae in amber piece 2 are equal in size, with an entire body length of about $1.8 \mathrm{~mm}$ (without appendages).

The neuropteran larvae can be identified as such based on their massive mouth parts forming a pair of gently curving stylets (with a length of about $1.3 \mathrm{~mm}$ in amber piece 1; about $1 \mathrm{~mm}$ in amber piece 2). The overall appearance of the larvae resembles that of owlfly and antlion larvae (Ascalaphidae + Myrmeleontidae) based on numerous characters: (a) the head is strongly squareshaped in dorsal or ventral view as typical for larvae of Ascalaphidae and their closely related groups; (b) stylets carry two prominent teeth each, as known for larvae of Ascalaphidae and Myrmeleontidae; (c) trunk segments 2 and 3, hence mesothorax and metathorax, have prominent protrusions dorsally.

The rather large head (about $0.8 \mathrm{~mm}$ in amber piece 1; $0.5 \mathrm{~mm}$ amber piece 2) in comparison to the relatively small trunk (about $1.2 \mathrm{~mm}$ in amber piece $1 ; 1.3 \mathrm{~mm}$ amber piece 2) indicates that these specimens are in early larval stages.

Remarks to phylogenetic position. - There have been several neuropteran larvae described from Cretaceous amber so far (e.g. Wang et al. 2016; Liu et al. 2016, 2018; Badano et al. 2018; Haug, C. et al. 2019; Haug, J.T. et al. 2019a, b, 2020a, b; Haug, G.T. et al. 2020). For many neuropteran groups and species, larvae have been described in detail (in contrast to many other insect groups), so more comprehensive data about larval morphology is available for extant representatives. However, larval specimens found in Myanmar amber show distinct variation in morphology compared to today living species. Character combinations that were found in neuropteran larvae, also particularly in myrmeleontiformian larvae, cannot be found in any extant form. Badano et al. (2018) assumed an ingroup position within Myrmeleontidae + Ascalaphidae for specimens of several fossil species described based on larvae, namely Electrocaptivus xui Badano, Engel \& Wang, 2018 in Badano et al. (2018), Burmitus tubulifer
Badano, Engel \& Wang, 2018 in Badano et al. (2018), Diodontognathus papillatus Badano, Engel \& Wang, 2018 in Badano et al. (2018), Mesoptynx unguiculatus Badano, Engel \& Wang, 2018 in Badano et al. (2018), and Adelpholeon lithophorus Badano, Engel \& Wang, 2018 in Badano et al. (2018) in Myanmar amber. The enclosed larvae of specimens PED 0083 and BUB 3391 differ in morphology from most of these: Electrocaptivus xui namely differs in mandibular shape and position of two tooth-like protrusions of the mandible. Burmitus tubulifer possesses three distinct mandibular teeth (in contrast to two teeth in the here presented specimen). Mesoptynx unguiculatus and Adelpholeon lithophorus differ in head shape (i.e. head longer than wide in M. unguiculatus and Adelpholeon lithophorus; head slenderer in posterior region than in here described nymphs); an enlarged tarsal claw of $M$. unguiculatus is not present in specimens of PED 0083 and BUB 3391; prominent projection at the base of the mandible as in A. lithophorus are not recognisable in PED 0083 and BUB 3391.

Diodontognathus papillatus shows distinct similarities to the morphology of larvae of both specimens, including shape and length of head and mandible, two mandibular teeth with several thin setae in between, antennae length less than one third of the mandible and globose eye tubercles (the latter is given as diagnostic for the species in Badano et al. 2018). However, cylindrical protuberances with setae seem not to be present at the head capsule of the larvae in PED 0083 and BUB 3391, which was given as main diagnostic feature of Diodontognathus papillatus by Badano et al. (2018). However, as the presence of two mandibular teeth seems rather uncommon and due to several similarities of the morphology especially to Diodontognathus, a close phylogenetic relationship to Diodontognathus Badano, Engel \& Wang, 2018 in Badano et al. 2018, Mesoptynx Badano, Engel \& Wang, 2018 in Badano et al. 2018, and Adelpholeon Badano \& Engel, 2018 in Badano et al. 2018 of the larvae in PED 0083 and BUB 3391 seems plausible.

Besides these, there are adult forms of Ascalaphidae and other neuropteran groups known from the Cretaceous (especially from the Crato Formation in Brazil), but it is not possible up to present knowledge to correlate these with known larval forms. For the Crato Formation as an example, the only known larvae of Myrmeleontiformia cannot be clearly identified to a modern linage due to the preservation (Herrera-Flórez et al. 2020).

\section{Dermaptera}

Amber piece 3 (repository number BUB 3150; Fig. 3) contains four similar-sized (about $1.8 \mathrm{~mm}$ without appendages) specimens of varying degrees of preservation. 


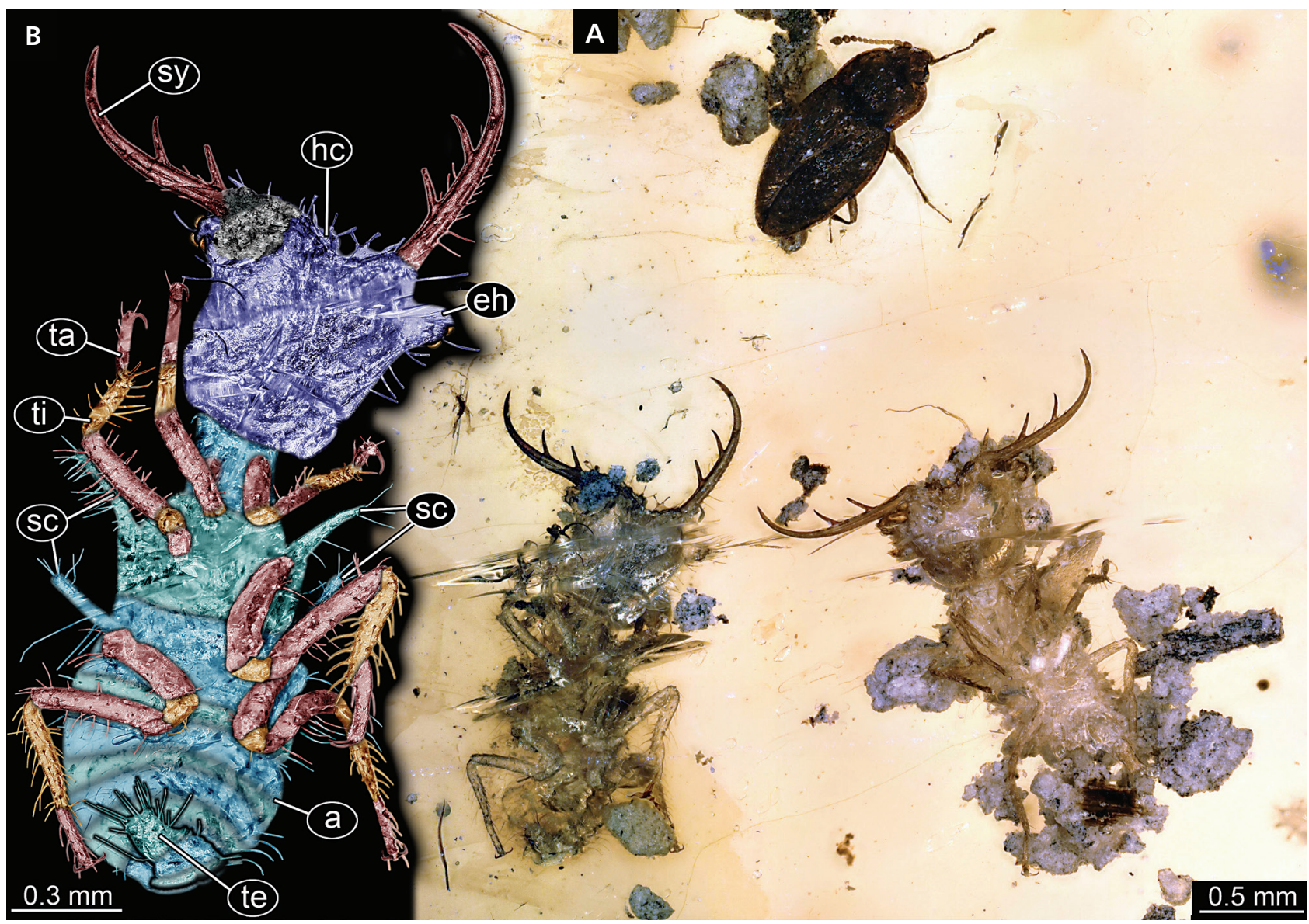

Figure 2. Amber piece with two owlfly-like larvae (repository number BUB 3391). A - composite image of the group; note the small beetle as syninclusion. B - colour-marked version of the left specimen in A. Abbreviations: a - abdomen; eh - eye hill; hc - head capsule; sc - scolus; sy - stylet; ta - tarsus; te - trunk end; ti - tibia.

The specimens can easily be identified as representatives of Dermaptera, earwigs, based on the morphology of the cerci (with about $0.5 \mathrm{~mm}$ length). These are prominent gently inward curved and lack sub-divisions; they appear rigid and sturdy. Head is prognathous and drop-shaped, with no ocelli apparent. The antennae, which is about $1 \mathrm{~mm}$ in length, is subdivided into at least 10 elements. Two tarsal elements of all legs are well recognisable, but there might be a third smaller element which cannot be located clearly. There are no elytrae or hind wings apparent, also no genital structures apparent.

Remarks to phylogenetic position. - An ingroup position of the specimens enclosed in BUB 3150 within Neodermaptera is assumed based on the absence of ocelli and subdivision of tarsi into less than five elements. An ingroup position of Karschiellidae and Diplatydae can be excluded, as the cerci of the specimens described herein are not subdivided. Also, Arixeniidae and Hemimeridae can be excluded, as these groups show a morphological adaptation to a parasitic lifestyle (Haas 2003, Ren et al. 2018).
Ren et al. (2018) reported two first-instar nymphs in Myanmar amber, which show several similarities in morphology, although they differ in size $(3.45-3.50 \mathrm{~mm}$ in Ren et al. $2018 v s .1 .8 \mathrm{~mm}$ of the herein reported nymphs). Based on the morphology of neck ("forficuloid neck" in Ren et al. 2018) and cerci, Ren et al. (2018) suggested a possible ingroup position of their specimens within Anisolabididae but could also not exclude a relationship to Labiduridae. However, as dermapterans (adults and nymphs) are still rarely described in Cretaceous amber (e.g. Engel \& Grimaldi 2014, Ren et al. 2017, 2018, Mao et al. 2020) and data about the morphology of early nymphs are lacking, a further reaching interpretation of the here reported nymphs to a specific dermapteran ingroup remains uncertain.

\section{Orthoptera}

Amber piece 4 (repository number BUB 3193; Fig. 4) contains three small "orthopteroid" appearing individuals. In all three, the thorax appendage 3 (hindleg) is signifi- 
cantly larger than the two anterior ones. Also, the femur (most proximal of the more elongate leg elements) is proximally thicker, appearing swollen. This indicates that all three are representatives of Orthoptera. Two specimens are of the same size ( 1 and 2; about $1.1 \mathrm{~mm}$ in body length without appendages), the third specimen is significantly larger (about $2.1 \mathrm{~mm}$ ), but otherwise appears rather similar. In all three, the antenna is rather long (about 1.1 $\mathrm{mm}$ ), especially in the larger one (about $1.6 \mathrm{~mm}$ ). This could indicate that these are representatives of Ensifera. Cerci are well apparent, but not especially long (about $0.3 \mathrm{~mm}$ and $0.2 \mathrm{~mm}$ respectively), no traces of developing wings apparent.

Remarks to phylogenetic position. - Although the group Orthoptera is very species-rich (more than 29,000 described species, Cigliano et al. 2021), representatives of Orthoptera have been rarely described in Myanmar amber up to now. Ross (2020) listed 11 formally described orthopteran species in total (in Ross 2021 no additional species were reported).

Many of the described species are representatives of the, today extinct, group Elcanidae (e.g. Poinar et al. 2007, Peñalver \& Grimaldi 2010, Fang et al. 2015, Heads et al. 2018, Kočárek 2020) which are characterised by distinct tibial spurs. These tibial spurs are not present at the here described specimens (Fig. 3, BUB 3150), so an ingroup position within Elcanidae can be excluded.

As no developing wings are visible, the orthopteran nymphs enclosed in specimen BUB 3193 likely represent early instars (note: while it cannot be fully excluded that these could be wingless forms, their habitus differs from representatives of lineages where such entirely wingless forms are known). There are no characters visible such as a tympanum (hearing organ at the front leg) or colour pattern. An ingroup position within Gryllotalpidae can be excluded by the morphology of the forelegs. Besides this, a further interpretation of the enclosed nymphs remains rather speculative. However, based on tarsal morphology and number of elements (less than four), a shorter tibia than femur at the hindleg (Poinar et al. 2020 and references therein) and general habitus, an ingroup position within Gryllidae seems plausible.

Grimaldi et al. (2002) reported eight specimens (six of the group Grylloidea), two nymphs putatively of the group Grylloidea have been depicted. Recently, a late instar of a female specimen of Gryllidae (Poinar et al. 2020) was described (Pherodactylus micromorphus Poinar Jr., Su \& Brown, 2020). The here described orthopteran nymphs (BUB 3193) cannot be conclusively interpreted as representatives of any formally described species (or genus) in Myanmar amber, as they differ significantly in morphology, or the known specimens represent adults or late immature stages. Due to the lack of data of orthopterans in Myanmar amber, but also of the morphology of early extant orthopteran nymphs, a further reaching interpretation is currently not possible.

\section{Collembola}

Amber piece 5 (repository number BUB 3162; Fig. 5) contains several dozens of specimens, among them 71 very tiny specimens all of the same size (about $0.35 \mathrm{~mm}$ without appendages) and shape. All the 71 specimens have very short antennae and only a few abdomen segments. This combination indicates that all the small specimens are springtails, hence representatives of the group Collembola. Further prominent syninclusions are, for example, an orthopteran and a fulgoromorphan.

Remarks to phylogenetic position. - An ingroup position of the collembolan specimen within Symphypleona and Neelipleona can be excluded by the presence of distinct visible segmentation of abdominal segments and general habitus. The first thoracic segment is well visible, abdominal segments are similar in length, and a prominent furcula is not visible, which would also exclude species within the group Entomobryomorpha (Christiansen \& Nascimbene 2006, Sánchez-García \& Engel 2016). Therefore, the individuals enclosed in amber piece BUB 3162 most likely represent Poduromorpha. Thus, as details of mouthparts, antennae and other fine structures are not accessible due to optical irregularities of the amber and the small size of the specimens, a further reaching interpretation is not possible.

Fossil representatives of Collembola can be found in various deposits and time epochs in the fossil record (summarised in Sánchez-García \& Engel 2016). Nearly all descriptions of Collembola in Myanmar amber are included in the extensive study of Christiansen \& Nascimbene (2006), in which 122 specimens were described, including 36 specimens of Poduromorpha (four of these could be identified further by the authors).

\section{Discussion}

\section{Case 1: Sociality in Neuroptera}

Observation in the modern fauna. - Usually the group Neuroptera is not considered when discussing sociality. Especially many of the larvae are known to be strictly solitary predators. They appear to be highly aggressive and territorial; hence they are to be expected not to be grouping together. Finding two larvae close together is therefore rather unusual. Yet, there are some exceptions to the solitary lifestyle among modern day representatives of Neuroptera. 


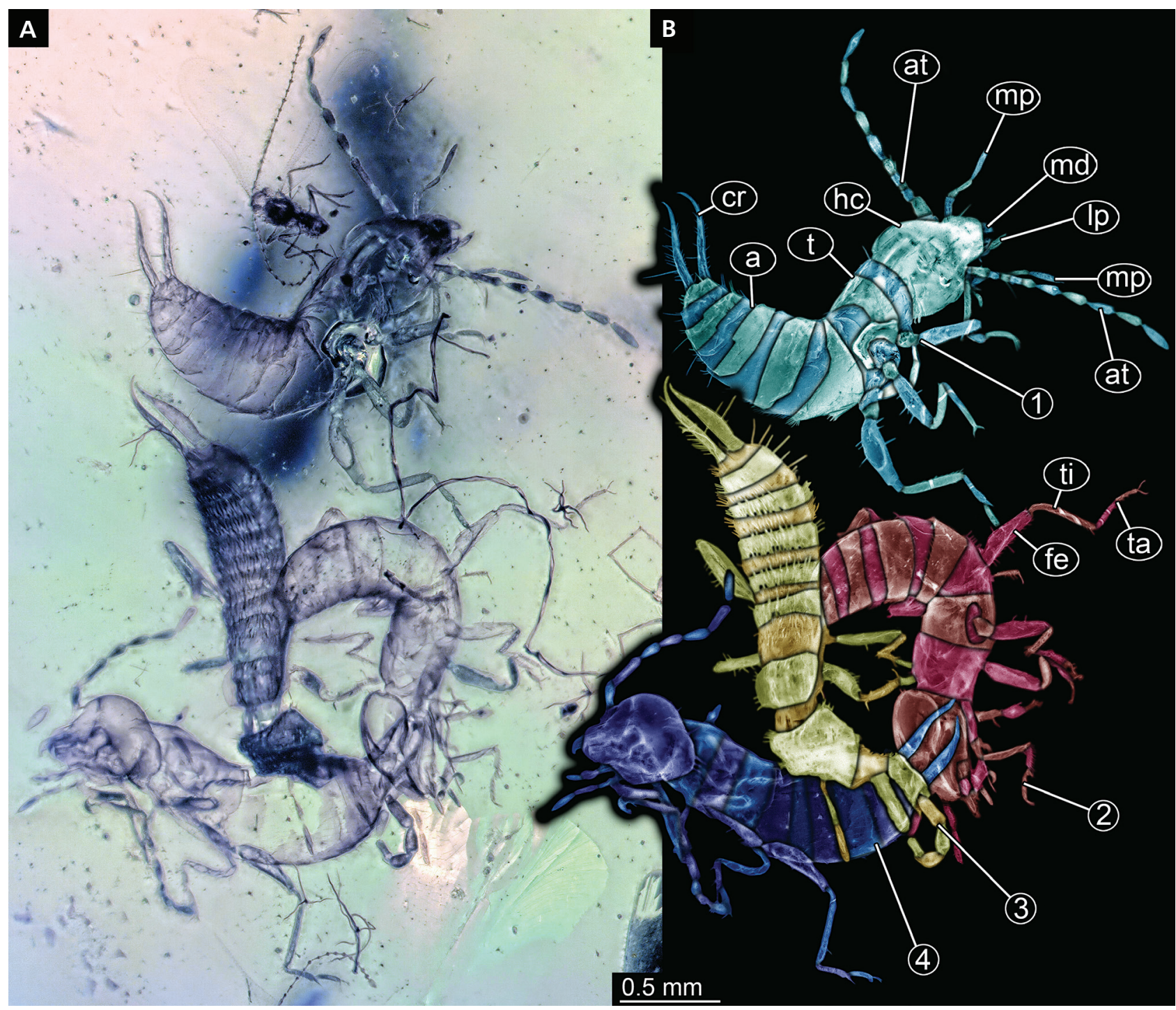

Figure 3. Amber piece with four earwig nymphs (repository number BUB 3150). A - composite image of the group of animals. B - colour-marked version of A. Abbreviations: 1-4 - number of specimen; a - abdomen; at - antenna; cr - cercus; fe - femur; hc - head capsule; lp - labial palp; $\mathrm{md}$ - mandible; $\mathrm{mp}$ - maxillary palp; $\mathrm{t}$ - thorax; ta - tarsus; ti - tibia.

Larvae of Nevrorthidae have been reported to occur in high abundances in fast-running streams in the extant fauna (Malicky 1984), leading to closer proximity of the individuals. It may therefore not be surprising that also cases are known in which several individuals of these larvae have been found in a single piece of amber (Wichard et al. 2009; Haug, J.T. et al. 2020a).

Another good chance to find several individuals of neuropterans together in amber is the moment of hatching. Eggs are often laid in groups by the mother, hence when hatching the individuals will be in close proximity before dispersing (see discussion in Hörnig et al. 2016). Indeed, Pérez-de la Fuente et al. (2019) recently reported such a spectacular case of hatching neuropteran larvae preserved in Lebanese amber.
In some cases, the neuropteran larvae will furthermore stay together after hatching, at least for some time, right where they hatched. Such behaviour is known for the larvae of certain owl flies (Ascalaphidae; Henry 1972). Eggs have been laid by the mother on a twig, and the larvae will remain on this twig closely together. If small prey becomes available, it will be consumed by a single individual, no sharing has been observed between the larvae. Yet, if larger predators approach, all individuals will perform a type of group defence: all of the larvae will open their massive mandibulo-maxillary stylets to fear off the predator (Henry 1972: fig. 9; simplified in Fig. 1D; Aspöck \& Aspöck 2007: abb. 41). Some type of defence has been reported for a variety of owlfly larvae (Westwood 1888, Froggatt 1907, Ghosh 1913, Tillyard 1926), 
yet it remains unclear whether this is in all cases such a coordinated group defence as reported by Henry (1972). Before moulting to the second larval stage, individuals will leave the twig apparently disperse to live a strictly solitary life. Yet, there is an indication that also adult owlflies may form stable groups, coming together at specific roosting sites (Gomes-Filho 2000).

Interpretation of the fossils. - The (at least) six specimens of owlfly-like larvae in close proximity preserved in a single piece of amber are challenging to interpret at first glance (Fig. 1). Most modern owlfly larvae are aggressive, also against their kin; hence it is extremely unlikely to even find two of them close together. An exception would be the moment of hatching. This seems unlikely to be the case here. All specimens appear well sclerotised, hence have already spent some time after hatching. If hatching would not have been highly strictly synchronised, it would not be expected to find six specimens close together. It seems therefore more likely that the fossil larvae spent at least some time actively aggregated together. The presence of scoli, setiferous structures on their anterior trunk, indicates that these should acquire camouflage at a certain point in their life. Yet, none of the specimens shows indication of camouflaging. This would be compatible with these specimens representing stage 1 larvae still forming a group with their siblings, similar to modern owlfly larvae. In fact, even the arrangement in the amber is reminiscent of the positioning of modern day defending owlfly larvae (Fig. 1D, redrawn after Henry 1972). This makes an interpretation of the amber piece as representing such a case of group defence at least plausible.

The other amber piece is less simple to interpret (Fig. 2). In how far could the finding of two owlfly-like larvae in a single piece of amber be interpreted as an indication of social behaviour? As pointed out, usually these predatory larvae are aggressive, fierce and solitary predators. Hence we should in principle not expect two of these larvae close enough together to find them in a single, rather small piece of amber. So, could these two larvae be just freshly hatched and simply not yet having dispersed? Unlike in the other amber piece, there are only two of them; hence this could be more likely. Yet, both specimens apparently have camouflaging objects on their back which must have been actively collected, hence it is more than unlikely that these larvae have just hatched.

Could these two larvae be part of a defending group? There are so far only few depictions of groups of defending owlfly larvae, yet in all cases, the condition of the larvae is quite clearly different from the specimens in amber at least in one aspect: the group-defending larvae lack camouflaging objects (Henry 1972: fig. 9; simplified in Fig. 1D; Aspöck \& Aspöck 2007: abb. 41), hence as in amber piece 1 .
This is not surprising, as there seems to be a clear correlation: owlfly larvae are "naked" when sitting on twigs, ground-living forms are carrying camouflaging objects (Henry 1977). As the individuals performing group defence in the modern fauna sit on a twig, they are naked; as they do also not leave the twig before their group defence, they do not have the opportunity to collect objects for camouflaging. When leaving the defending group, the individuals will start collecting debris for building up their camouflaging (Henry 1977). At least in some species performing coordinated group defence, the dispersal appears to be strictly synchronised (Henry 1977). In such a case we could expect that around the abandoned twig owlfly larvae remain in closer association while they assemble their "camouflaging cloak".

We can therefore speculate that the two fossil larvae are indeed in this special phase of their life. Both of them have a similar morphology, indicative of an early stage owlfly larva; also the size is compatible with this assumption. Both have already camouflaging debris on their back, and still they have apparently been trapped in close association to each other.

A mere by-chance co-occurrence of the two owlfly larvae of the same type and the same developmental stage seems more unlikely. Taken together these two pieces, we conclude that the fossils provide an indirect indication that temporary gregarious behaviour known in modern owlfly larvae was already performed by more distantly related lacewing larvae back in the Cretaceous.

\section{Case 2: Sociality in Dermaptera}

Observation in the modern fauna. - Many derived species of earwigs are known to provide extensive brood care and also show other types of sub-social behaviour (e.g. Günther \& Herter 1974, Lamb 1976). As a pre-requisite, the immature earwigs must live in groups, otherwise the mother could not care for her offspring (see discussion in Hörnig et al. 2016). These groups seem to stay also together when the mother is absent, at least during the first nymphal stage. Many species disperse shortly before moulting to the next stage. Only in few species also stage two nymphs remain in groups with the mother (Lamb 1976).

There is not only interaction between the mother and the offspring, but there is also interaction between the siblings, including exchange of food (Falk et al. 2014, Kramer et al. 2015). The group formation in earwigs is therefore not only directly coupled to the care of the mother; even if the mother is absent, the immature earwigs have clear advantages by staying in a group.

Interestingly, group defence, as discussed above, has not been reported in earwig immatures. The formation of dense defence positions especially in groups of immatures 


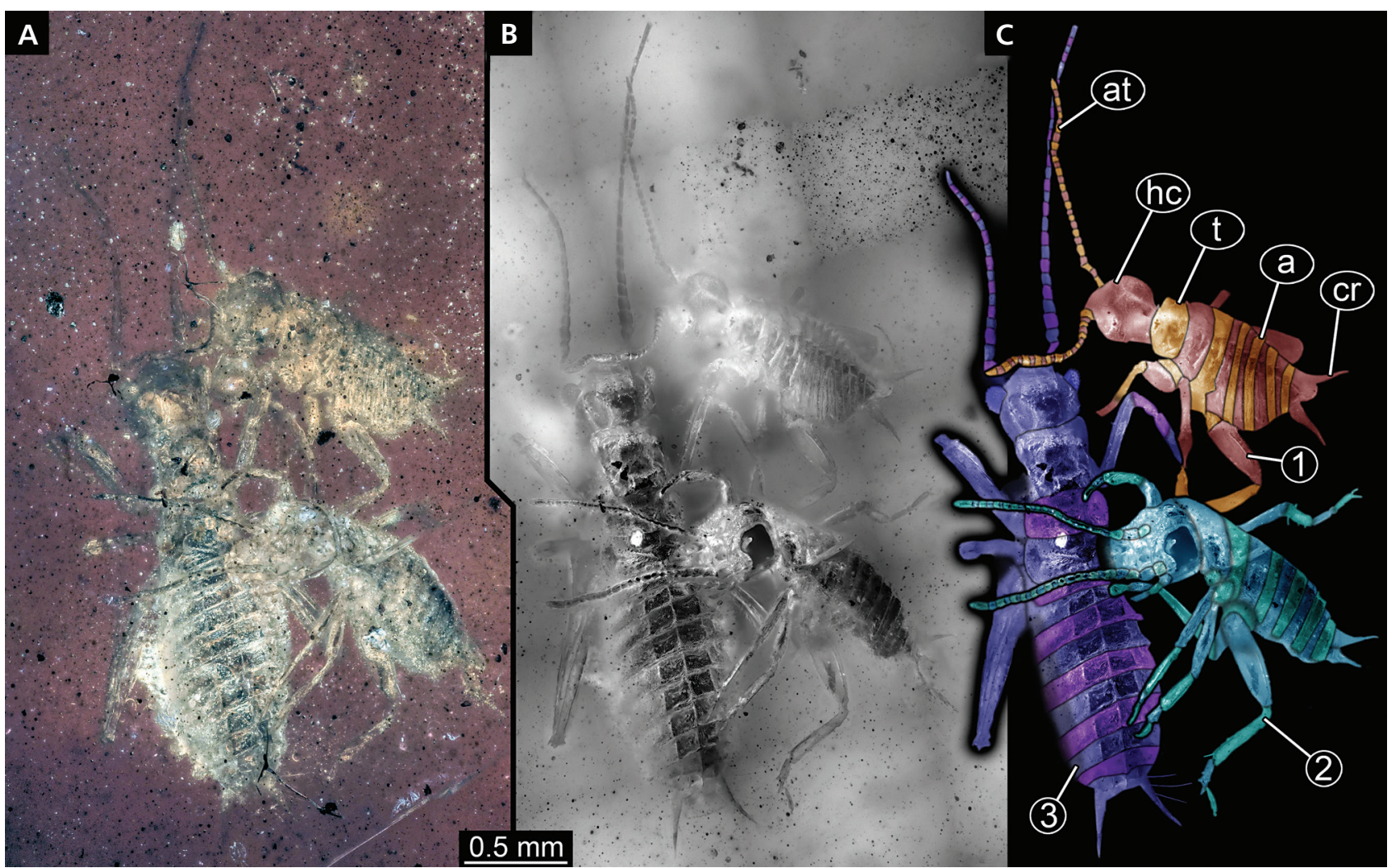

Figure 4. Amber piece with three orthopteran nymphs (repository number BUB 3193). A - composite image of the group of animals. B - fluorescence image of the group of animals. C - colour-marked version of B. Abbreviations: 1-3 - number of specimen; a - abdomen; at - antenna; cr - cercus; $\mathrm{hc}$ - head capsule; $\mathrm{t}$ - thorax.

appears to be highly advantageous (e.g. Jolivet et al. 1990, Dury et al. 2014). Also earwigs indeed possess an effective structure to fear off predators, their cerci. These are not yet as massive and fierce-appearing as in adults, yet already nymphs are able to grasp prey with their cerci, and they also show aggressive behaviour using their cerci (Matzke \& Klass 2005). Still earwigs do not use these structures in a group defence.

Instead, earwigs seem to disperse when disturbed (Matzke \& Klass 2005) and re-aggregate later. It is quite astonishing that, although the group works effectively together and all members of it possess structures that could be used for defence, this is not used to perform a coordinated defence. This is especially astonishing as it appears to be a very effective strategy in so many other groups (Henry 1972, Jolivet et al. 1990, Dury et al. 2014). Apparently, such group defence must be coupled to a specific cost, acting against the presence of it in a group such as Dermaptera.

Interpretation of the fossils. - The amber piece clearly includes four nymphal earwigs (Fig. 3). All appear quite similar, and differences can well be interpreted as caused by preservational effects. The specimens could therefore well represent several individuals from a group of nymphs that hatched from the same clutch. Engel (2009) reported a comparable find, remains of four nymphs preserved in a small piece of French Cretaceous amber. Engel (2009) argued that based on the elongated shape of the proximal elements of the antenna the specimens could only represent early stage nymphs, most likely first instar nymphs. The same morphology can be seen in the here reported specimens. Unfortunately, many details are not accessible in the here reported specimens. Yet, it appears that the tarsi are not subdivided into five tarsus elements, but only into two or three; ocelli seem to be absent. This would indicate an ingroup position within Neodermaptera.

Engel (2009) argued that the specimens in the piece of amber he described being preserved close together is indicative for parental care (see discussion in Hörnig et al. 2016). As discussed above, the mother might in fact have already abandoned the nymphs, but they could still have stayed together; this also applies for the here presented fossil. In any case, earwigs apparently have performed a kind of social behaviour 100 million years ago.

Specimens in BUB 3150 represent a rare case of several early (presumably first) instar dermapterans preserved in one amber piece, which is an important finding for reconstruction of the evolution of brood care within the group. 


\section{Case 3: Sociality in Orthoptera}

Observation in the modern fauna. - Different representatives of Orthoptera are well-known for forming groups, i.e. showing gregarious behaviour. This seems to be strongly coupled to the density of individuals, which appears to be limited by different factors, such as food availability (e.g. Szinwelski et al. 2015). Some species are specifically famous for their facultative adult gregarious forms forming gigantic swarms with enormous ecological and also socio-economical impact, most notably Schistocerca gregaria (Forskål, 1775) (e.g. Simpson et al. 2001, 2002) and Locusta migratoria Linnaeus, 1758 (e.g. Ellis 1953, Greenwood \& Chapman 1984).

Forming groups appears to be beneficial in several aspects for orthopterans. Aggregation apparently prohibits dehydration (Yoder et al. 2002), i.e. group formation changes the micro-climate (Bell et al. 2007; see also discussion in Hörnig et al. 2016). It has furthermore been observed that immature (= nymphal) orthopterans living in a group develop faster, i.e. need fewer instars to reach adulthood (Watler 1982). The exact cause seems to be still unclear. Food sharing between siblings or extended care by the mother seem not to be present in such groups. The aggregation of immatures is active, i.e. they use chemical traits (McFarlane et al. 1983), more precisely pheromones (Nagel \& Cade 1983) to keep the coherence of the group.

Similar to the case in earwigs it is partly surprising that there is no group defence behaviour known it orthopterans. As lain out for earwigs, orthopterans are capable of defending themselves effectively. Their third thoracic appendages or hindlegs bear numerous spines and are able to perform a destructive defensive kicking motion (Field 1980, Burrows \& Wolf 2002). With the same musculature also an escape jump can be performed. It seems more likely that threatened groups of orthopterans will disperse by escape jumps and later re-aggregate (comparable to earwigs).

Interpretation of the fossils. - The three orthopteran nymphs are preserved closely together, even overlaying each other (Fig. 4). The nymphs differ significantly in size. This indicates that they are different nymphal stages. The literature gives no detailed information about the structure of modern groups of nymphs, but it seems reasonable that such groups include individuals of different stages. It seems not too common to have several orthopterans in a single piece of amber. Hence the fossil piece is a rare case. Still this case is less simple to interpret compared to the ones above. Larvae of Ascalaphidae and nymphs of Dermaptera in later stages are known to be highly aggressive and territorial. Hence, it is unlikely to find them together just by chance. Modern orthopterans are not known to show such a strong aggressiveness. It could therefore well be possible that the three nymphs did not actively aggregate but were just embedded together by chance because there were rather high abundances of individuals. It remains therefore partly unclear if the fossil specimens are indicative of active aggregation behaviour. Still the find is rare, and it is still possible that we face active aggregation in orthopterans already 100 million years ago.

\section{Case 4: Sociality in Collembola}

Observation in the modern fauna. - Springtails (Collembola) are even less recognised for showing social behaviour than the groups discussed above. Despite that, springtails are well known to be attracted by chemical substances (e.g. Salmon et al. 2019), resulting in aggregations of individuals (e.g. Usher 1969, Verhoef \& Nagelkerke 1977). This includes interspecific chemical factors (kairomones) such as excreta of earthworms (Salmon \& Ponge 2001), but also active intraspecific chemical factors, i.e. pheromones (Purrington et al. 1991, Manica et al. 2001, Benoit et al. 2009). The active aggregation appears to provide several benefits for the springtails: 1) Living in groups appears to change the micro-climate and with this reduces water loss (as also discussed for Orthoptera). 2) It increases mate access. As many springtails are part of the soil fauna, mobility is limited by the environment and hence finding a possible mate is more challenging. Actively stabilising groups is therefore beneficial in this aspect. 3) Partly coupled to point 2 , active aggregation overall stabilises populations of Collembola in areas with adequate food and moisture resources. Furthermore, the same pheromone triggers egglaying of females. In combination, it will allow immatures to develop in optimal habitats. Springtails are not known to show further-reaching aspects of interaction. There is no report on brood care, food sharing or group defence.

Interpretation of the fossils. - The amber piece includes a vast number of specimens (more than 70; Fig. 5), possibly representing Poduromorpha. All specimens appear to be more or less of the same, rather small size. They are, based on their size, most likely immature forms. The amber piece also shows quite some syninclusions: (a) a rather large and not very well-preserved specimen, most likely a representative of Auchenorrhyncha (close to specimen 10); (b) a larger specimen, possibly a nymphal stage of Orthoptera (close to specimen 71); (c) a smaller beetle (close to specimen 28); (d) a possible spider (close to specimen 13); (e) isolated legs most likely of representatives of Insecta (one, for example, close to specimen 9); (f) a lot of dirt. 


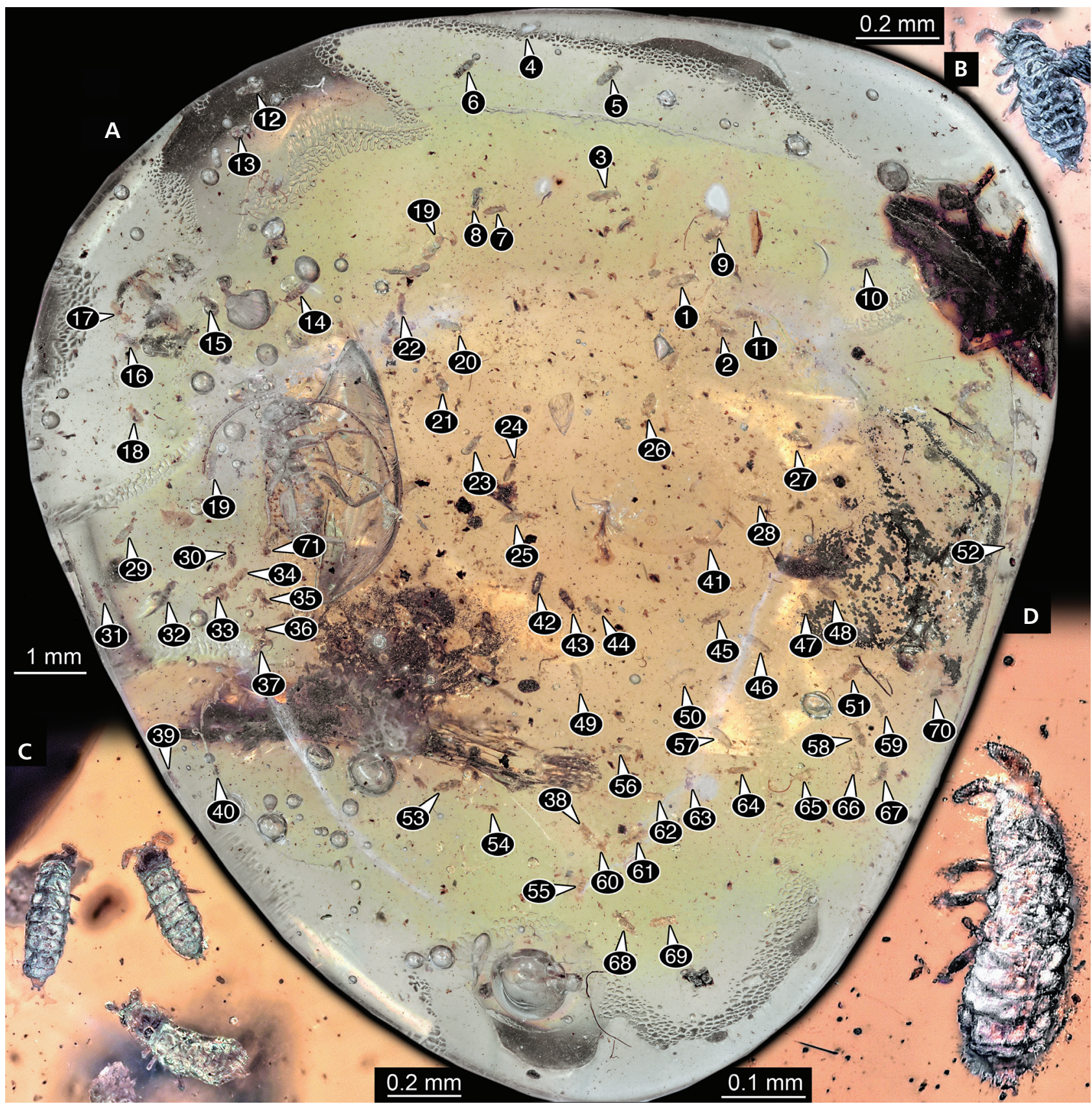

Figure 5. Amber piece with $>70$ individuals of Collembola (repository number BUB 3162). A - composite image of the group of animals. B-D - close-up images of several individuals shown in A. Abbreviations: 1-71 - number of specimen.

The amber piece most likely formed at the ground, preserving a piece of the soil fauna. However, as rafting in open water was observed in Collembola linked with huge aggregations of individuals (e.g. Hawes et al. 2008), also capturing of the collembolans in fresh resin on water surface would be in principle possible, as also other marine arthropods are known from Myanmar amber (e.g. Schädel et al. 2021). The fact that all specimens have the same size could indicate that all specimens originated from a single clutch of eggs. The close association of the specimens may therefore not represent a case of active aggregation, but instead a time phenomenon, i.e. they might simply not yet have dispersed. Still, we can also suggest that these forms, like their modern representatives, actively grouped together to stabilise their population and future mating chances. The amber piece is at least compatible with such an interpretation. There are two similar cases described for Collembola; one piece of Spanish amber (of Albian age) with 45 individuals (Sánchez-Garcia et al. 2018) and a further one of Dominican amber (Miocene; Poinar Jr \& Poinar 1999). 


\section{Conclusions}

Preserved cases of fossil representatives of Insecta performing possible active gregarism have rarely been described in the literature. This is not necessarily due to only rare findings of fossilised groups of conspecific individuals (with more than three individuals), but possibly due to the point that gregarism (or aggregation behaviour) of fossil species appears to be rarely regarded as sufficiently important to be reported.

The four cases discussed here may all represent the active aggregation of immature representatives of Insecta. The individual cases are more or less well-founded yet remain possible cases without strong indications for sociality. This is not only caused by the fact that fossil finds are difficult to interpret. It is also caused by our still quite limited knowledge of extant counterparts. This is astonishing as all discussed cases show behaviour aspects associated with eusocial behaviour, a phenomenon of central interest for evolutionary-ecological research.

All the cases discussed here indicate that there is no strict order in the evolution of social behaviour. Modern larvae of Ascalaphidae, i.e. owlflies, do not show most of the aspects of social behaviour, but perform a highly specialised type of group defence. Nymphal orthopterans and even more so earwigs show more aspects of social behaviour, yet do not perform group defence. This is partly astonishing as both are in principal equipped to perform such actions. It therefore seems that the behavioural aspects characterising eusociality can evolve in a rather mosaic-like pattern.

The fossils presented here provide possible minimum ages for such types of behaviour in these groups. Especially in the case of owlfly relatives this seems well founded. Also, in the case of earwigs it seems likely, and also represents the second such record (Engel 2009). For orthopterans and collembolans, the interpretation as cases of active aggregation is possible but not compelling.

Finding fossils together in a single piece of amber should always trigger the question: why are these two (or more) specimens preserved together? Furthermore, the findings presented here should trigger more research on extant animals; currently, our knowledge on the evolution of sociality is still heavily underdeveloped.

\section{Acknowledgements}

We thank Bo Wang and one anonymous reviewer for helpful comments on the manuscript. The Volkswagen Foundation kindly funds JTH with a Lichtenberg Professorship. MKH, JTH and $\mathrm{CH}$ thank J.M. Starck, Munich, and S. Harzsch, Greifswald, for their continuous support. U. Wimmer, Munich, is thanked for her help with imaging and subsequent processing. We highly appreciate the effort of all people involved in providing open access, open source and low-cost software. This is LEON publication \#17.

\section{References}

Arillo, A.A. 2007. Paleoethology: fossilized behaviours in amber. Geologica Acta 5(2), 159-166.

AsPöск, U. \& Aspöck, H. 2007. Verbliebene Vielfalt vergangener Blüte. Zur Evolution, Phylogenie und Biodiversität der Neuropterida (Insecta: Endopterygota). Denisia 20, Kataloge der Oberöstereichischen Landesmuseen Neue Serie 66, 451-516.

BABcock, L.E. 2003. Trilobites in Paleozoic predator-prey systems, and their role in reorganization of early Paleozoic ecosystems, 55-92. In Kelley, P., Kowalewski, M. \& Hansen, T.A. (eds) Predator-prey interactions in the fossil record. Springer, Boston, MA.

DOI 10.1007/978-1-4615-0161-9_4

Badano, D., Engel, M.S., Basso, A., Wang, B. \& Cerretti, P. 2018. Diverse Cretaceous larvae reveal the evolutionary and behavioural history of antlions and lacewings. Nature Communications 9, art. 3257. DOI 10.1038/s41467-018-05484-y

BARdEN, P. \& Grimaldi, D.A. 2016. Adaptive radiation in socially advanced stem-group ants from the Cretaceous. Current Biology 26(4), 515-521. DOI 10.1016/j.cub.2015.12.060

Bell, W.J., Roth, L.M. \& Nalepa, C.A. 2007. Cockroaches: Ecology, Behavior, and Natural History. 230 pp. JHU Press, Baltimore.

Benoit, J.B., Elnitsky, M.A., Schulte, G.G., Lee, R.E. \& Denlinger, D.L. 2009. Antarctic collembolans use chemical signals to promote aggregation and egg laying. Journal of Insect Behavior 22(2), 121-133.

DOI 10.1007/s10905-008-9159-7

Béthoux, O., Galtier, J. \& Nel, A. 2004. Earliest evidence of insect endophytic oviposition. Palaios 19(4), 408-413. DOI 10.1669/0883-1351(2004)019<0408:EEOIEO>2.0.CO;2

Boucot, A.J. 1990. Evolutionary paleobiology of behavior and coevolution. 725 pp. Elsevier, Amsterdam.

Boucot, A.J. \& PoInAR, G.O., JR 2010. Fossil behavior compendium. 424 pp. CRC Press, Boca Raton. DOI 10.1201/9781439810590

Bromley, R.G. 1996. Trace fossils: biology, taxonomy and applications. 361 pp. Chapman \& Hall, London. DOI 10.1007/978-1-4899-2875-7

Browne, F.G. 1971. Austroplatypus, a new genus of the Platypodidae (Coleoptera) infesting living Eucalyptus trees in Australia. Commonwealth Forestry Review 50, 49-50.

Burrows, M. \& Wolf, H. 2002. Jumping and kicking in the false stick insect Prosarthria teretrirostris: kinematics and motor control. Journal of Experimental Biology 205(11), 1519-1530. DOI 10.1242/jeb.205.11.1519

Camacho, L., Keil, C. \& Dangles, O. 2014. Factors influencing egg parasitism in sub-social insects: insights from the tree- 
hopper Alchisme grossa (Hemiptera, Auchenorrhyncha, Membracidae). Ecological Entomology 39(1), 58-65.

DOI 10.1111/een.12060

Cantil, L.F., Sánchez, M.V., Bellosi, E.S. \& Genise, J.F. 2018. Beyond Coprinisphaera: fossil nests of dung beetles. Lethaia 51, 444-455. DOI 10.1111/let.12258

Christiansen, K. \& Nascimbene, P. 2006. Collembola (Arthropoda, Hexapoda) from the mid Cretaceous of Myanmar (Burma). Cretaceous Research 27, 318-363.

DOI 10.1016/j.cretres.2005.07.003

Cigliano, M.M., Braun, H., Eades, D.C. \& Otte, D. 2021. Orthoptera Species File. Version 5.0/5.0. [08/2021]. http:// Orthoptera.SpeciesFile.org

CostA, J.T. 2018. The other insect societies: overview and new directions. Current Opinion in Insect Science 28, 40-49. DOI 10.1016/j.cois.2018.04.008

CREsPI, B.J. 1992. Eusociality in Australian gall thrips. Nature 359(6397), 724-726. DOI 10.1038/359724a0

Curtis, J. 1833. British Entomology. Volume 10. 434-481pp. John Cumberland, London.

Danforth, B.N., Conway, L. \& Ji, S. 2003. Phylogeny of eusocial Lasioglossum reveals multiple losses of eusociality within a primitively eusocial clade of bees (Hymenoptera: Halictidae). Systematic Biology 52(1), 23-36. DOI 10.1080/10635150390132687

Dressler, R.L. 1982. Biology of the orchid bees (Euglossini). Annual Review of Ecology and Systematics 13(1), 373-394. DOI 10.1146/annurev.es.13.110182.002105

Ducke, A. 1907. Nouveau genre de Sphégides. Annales de la Société entomologique de France 76, 28-30.

Dury, G.J., Bede, J.C. \& Windsor, D.M. 2014. Preemptive circular defence of immature insects: definition and occurrences of cycloalexy revisited. Psyche: A Journal of Entomology 2014, art. 642908, 1-13.

DOI $10.1155 / 2014 / 642908$

Eickwort, G.C. 1981. Presocial insects. 199-279. In HermanN H.R. (ed.) Social insects, Vol. 2. Academic Press, New York. DOI 10.1016/B978-0-12-342202-6.50010-1

Ellis, P.E. 1953. Social aggregation and gregarious behaviour in hoppers of Locusta migratoria migratorioides (R. \& F.). Behaviour 5, 225-260. DOI 10.1163/156853953X00122

ENGEL, M.S. 2009. Gregarious behaviour in Cretaceous earwig nymphs (Insecta, Dermaptera) from southwestern France. Geodiversitas 31(1), 129-135. DOI 10.5252/g2009n1a11

Engel, M.S. \& Grimaldi, D.A. 2014. New mid-Cretaceous earwigs in amber from Myanmar (Dermaptera). Novitates Paleoentomologicae 6, 1-16. DOI 10.17161/np.v0i6.4676

Evenhuis, N.L. 2021. The insect and spider collections of the world website. Accessed March 16, 2021. http://hbs. bishopmuseum.org/codens/

Falk, J., Wong, J.W.Y., Kölliker, M. \& Meunier, J. 2014. Sibling cooperation in earwig families provides insights into the early evolution of social life. The American Naturalist 183, 547-557. DOI 10.1086/675364

FAnG, Y., Wang, B., Zhang, H., Wang, H., Jarzembowski, E.A., Zheng, D., Zhang, Q., Li, S. \& LiU, Q. 2015. New Cretaceous
Elcanidae from China and Myanmar (Insecta, Orthoptera). Cretaceous Research 52, Part B, 323-328.

DOI 10.1016/j.cretres.2014.05.004

FatKa, O., Budil, P. \& Grigar, L. 2015. A unique case of healed injury in a Cambrian trilobite. Annales de Paléontologie 101(4), 295-299. DOI 10.1016/j.annpal.2015.10.001

Field, L.H. 1980. Observations on the biology of Deinacrida connectens (Orthoptera: Stenopelmatidae), an alpine weta. New Zealand Journal of Zoology 7(2), 211-220.

DOI 10.1080/03014223.1980.10423778

Fischer, T.C. \& Hörnig, M.K. 2019. Mating moths (Tineidae, Ditrysia, Lepidoptera) preserved as frozen behavior inclusion in Baltic Amber (Eocene). Palaeontologia Electronica 22(1), $1-11$. DOI 10.26879/829

Flemming, B.W. 2004. 75 Jahre Senckenberg am Meer Aktualismus als Forschungsprinzip. Natur und Museum 134(1), 1-20.

FORSKÅL, P. 1775. Descriptiones Animalium Avium, Amphibiorum, Piscium, Insectorum, Vermium; quae in Itinere Orientall observati Petrus Forskal. Prof. Haun. Post morten Acutoris editt Carsten Nieburhr. 164 pp. Hauniae.

DOI 10.5962/bhl.title. 2154

Froggatt, W.W. 1906. Notes on the hymenopterous genus Megalyra Westw., with descriptions of new species. Proceedings of the Linnean Society of New South Wales 31, 399-407.

Froggatt, W.W. 1907. Australian insects. 449 pp. William Brooks and Company, Sydney.

Fu, D., Ortega-Hernández, J., Daley, A.C., Zhang, X. \& Shu, D. 2018. Anamorphic development and extended parental care in a 520 million-year-old stem-group euarthropod from China. BMC Evolutionary Biology 18(1), art. 147. DOI 10.1186/s12862-018-1262-6

Genise, J.F., Sánchez, M.V., Bellosi, E.S., Cantil, L.F., Krause, J.M., González, M.G., Sarzetti, L.C., Verde, M., Puerta, P. \& Frana, J. 2017. Cricket oviposition trace fossils in palaeosols and their stratigraphic significance: The South American Palaeosol Ichnofossil Ages (SAPIAs). Palaeogeography, Palaeoclimatology, Palaeoecology 481, 64-76. DOI 10.1016/j.palaeo.2017.05.025

Ghosh, C.C. 1913. Life-history of Helicomitus dicax, Walker. Journal of the Bombay Natural History Society 22, 643-648.

Gibbs, J., Brady, S.G., Kanda, K. \& Danforth, B.N. 2012. Phylogeny of halictine bees supports a shared origin of eusociality for Halictus and Lasioglossum (Apoidea: Anthophila: Halictidae). Molecular Phylogenetics and Evolution 65(3), 926-939. DOI 10.1016/j.ympev.2012.08.013

Gomes-Filho, A. 2000. Aggregation behavior in the Neotropical owlfly Cordulecerus alopecinus (Neuroptera: Ascalaphidae). Journal of the New York Entomological Society 108(3), 304-314. DOI 10.1664/0028-7199(2000)108[0304:ABITNO]2.0.CO;2

Goulson, D. 2003. Bumblebees: their behaviour and ecology. 235 pp. Oxford University Press, USA.

Greenwood, M. \& Chapman, R.F. 1984. Differences in numbers of sensilla on the antennae of solitarious and gregarious Locusta migratoria L. (Orthoptera: Acrididae). International Journal of Insect Morphology and Embryology 13(4), 295-301. DOI 10.1016/0020-7322(84)90004-7 
Grimaldi, D.A. 1996. Captured in amber. Scientific American 274(4), 84-91. DOI 10.1038/scientificamerican0496-84

Grimaldi, D.A., Engel, M.S., \& Nascimbene, P.C. 2002. Fossiliferous Cretaceous amber from Myanmar (Burma): its rediscovery, biotic diversity, and paleontological significance. American Museum Novitates 3361, 1-71.

DOI 10.1206/0003-0082(2002)361<0001:FCAFMB >2.0.CO;2

GröHN, C. 2015. Einschlüsse im baltischen Bernstein. 424 pp. Wachholtz Verlag-Murmann Publishers, Hamburg.

Günther, K. \& Herter, K. 1974. 11. Ordnung Dermaptera (Ohrwürmer), 1-158. In Helmcke, J.G., Starck, D. \& Wermuth, H. (eds) Handbuch der Zoologie 4 (2) 2/11. De Gruyter, Berlin.

HAAs, F. 2003. 12. Ordnung Dermaptera, Ohrwürmer, 173-180. In Dathe H.H. (ed.) Lehrbuch der Speziellen Zoologie, Band I: Wirbellose Tiere, 5. Teil: Insecta. Spektrum Akademischer Verlag, Heidelberg, Berlin.

Harari, A.R., Ben-Yakir, D. \& Rosen, D. 1994. Mechanism of aggregation behavior in Maladera matrida Argaman (Coleoptera: Scarabaeidae). Journal of Chemical Ecology 20(2), 361-371. DOI 10.1007/BF02064443

Haug, C., Shannon, K.R., Nyborg, T. \& Vega, F.J. 2013. Isolated mantis shrimp dactyli from the Pliocene of North Carolina and their bearing on the history of Stomatopoda. Bolétin de la Sociedad Geológica Mexicana 65, 273-284. DOI 10.18268/BSGM2013v65n2a9

Haug, C., Herrera-Flórez, A.F., Müller, P. \& Haug, J.T. 2019. Cretaceous chimera-An unusual 100-million-year old neuropteran larva from the "experimental phase" of insect evolution. Palaeodiversity 12, 1-11.

DOI 10.18476/pale.v12.a1

Haug, G.T., Haug, C., Pazinato, P.G., Braig, F., Perrichot, V., Gröhn, C., Müller, P. \& Haug, J.T. 2020. The decline of silky lacewings and morphological diversity of long-nosed antlion larvae through time. Palaeontologia Electronica 23(2), art. a39. DOI 10.26879/1029

Haug, J.T. \& Haug, C. 2017. Species, populations and morphotypes through time - challenges and possible concepts. BSGF - Earth Sciences Bulletin 188, art. 20.

DOI $10.1051 /$ bsgf/2017181

Haug, J.T., Haug, C. \& Ehrlich, M. 2008. First fossil stomatopod larva (Arthropoda: Crustacea) and a new way of documenting Solnhofen fossils (Upper Jurassic, Southern Germany). Palaeodiversity 1, 103-109.

Haug, J.T., Haug, C., Kutschera, V., Mayer, G., Maas, A., Liebau, S., Castellani, C., Wolfram, U., Clarkson, E.N.K. \& WALOSZEK, D. 2011. Autofluorescence imaging, an excellent tool for comparative morphology. Journal of Microscopy 244, 259-272. DOI 10.1111/j.1365-2818.2011.03534.x

Haug, J.T., Waloszek, D., Maas, A., Liu, Y. \& Haug, C. 2012. Functional morphology, ontogeny and evolution of mantis shrimp-like predators in the Cambrian. Palaeontology 55, 369-399. DOI 10.1111/j.1475-4983.2011.01124.x

Haug, J.T., Caron, J.-B. \& Haug, C. 2013. Demecology in the Cambrian: synchronized molting in arthropods from the Burgess Shale. BMC Biology 11, art. 64.

DOI 10.1186/1741-7007-11-64
Haug, J.T., Nagler, C., Haug, C. \& HöRnig, M.K. 2017. A group of assassin fly pupae preserved in a single piece of Eocene amber. Bulletin of Geosciences 92, 283-295.

DOI 10.3140/bull.geosci.1621

Haug, J.T., Müller, P. \& Haug, C. 2018. The ride of the parasite: a 100-million-year old mantis lacewing larva captured while mounting its spider host. Zoological Letters 4, art. 31.

DOI 10.1186/s40851-018-0116-9

Haug, J.T., Müller, P. \& Haug, C. 2019a. A 100-millionyear old predator: a fossil neuropteran larva with unusually elongated mouthparts. Zoological Letters 5, art. 29. DOI 10.1186/s40851-019-0144-0

Haug, J.T., Müller, P. \& Haug, C. 2019b. A 100-million-year old slim insectan predator with massive venom-injecting stylets - a new type of neuropteran larva from Burmese amber. Bulletin of Geosciences 94, 431-440.

DOI 10.3140/bull.geosci.1753

Haug, J.T., Baranov, V., Schädel, M., Müller, P., Gröhn, P. \& Haug, C. 2020a. Challenges for understanding lacewings: how to deal with the incomplete data from extant and fossil larvae of Nevrorthidae? (Neuroptera). Fragmenta entomologica 52, 137-167. DOI 10.4081/fe.2020.472

Haug, J.T., Pazinato, P.G., Haug, G.T. \& Haug, C. 2020b. Yet another unusual new type of lacewing larva preserved in 100-million-year old amber from Myanmar. Rivista Italiana di Paleontologia e Stratigrafia 126, 821-832.

Hawes, T.C., Worland, M.R., Bale, J. S. \& Convey, P. 2008. Rafting in Antarctic collembola. Journal of Zoology 274(1), $44-50$.

Heads, S.W., Thomas, M.J., \& Wang, Y. 2018. A new genus and species of Elcanidae (Insecta: Orthoptera) from Cretaceous Burmese amber. Zootaxa 4527(4), 575-580.

DOI 10.11646/zootaxa.4527.4.8

Henry, C.S. 1972. Eggs and rapagula of Ululodes and Ascaloptynx (Neuroptera: Ascalaphidae): a comparative study. Psyche: A Journal of Entomology 79(1-2), 1-22. DOI 10.1155/1972/54050

Henry, C.S. 1977. The behavior and life histories of two North American ascalaphids. Annals of the Entomological Society of America 70(2), 179-195. DOI 10.1093/aesa/70.2.179

Herrera-Flórez, A.F., Braig, F., Haug, C., Neumann, C., Wunderlich, J., Hörnig, M.K. \& Haug, J.T. 2020. Identifying the oldest larva of a myrmeleontiformian lacewing a morphometric approach. Acta Palaeontologica Polonica 65, 235-250. DOI 10.4202/app.00662.2019

Hölldobler, B. \& Wilson, E.O. 1990. The ants. 746 pp. Harvard University Press, Cambridge. DOI 10.1007/978-3-662-10306-7

Hörnig, M.K., Sombre, A., Haug, C., Harzsch, S. \& Haug, J.T. 2016. What nymphal morphology can tell us about parental investment - a group of cockroach hatchlings in Baltic Amber documented by a multi-method approach. Palaeontologia Electronica 19(1), art. 5a. DOI 10.26879/571

Hörnig, M.K., Haug, J.T. \& Haug, C. 2017. An exceptionally preserved 110 million years old praying mantis provides new insights into the predatory behaviour of early mantodeans. PeerJ 5, art. e3605. DOI 10.7717/peerj.3605 
Hörnig, M.K., Haug, C., Schneider, J.W. \& Haug, J.T. 2018. Evolution of reproductive strategies in dictyopteran insectsclues from ovipositor morphology of extinct roachoids. Acta Palaeontologica Polonica 63, 1-24. DOI 10.4202/app.00324.2016

HörNIG, M.K., FISCHER, T.C. \& HAUG, J.T. 2019. Caught in the act of hatching-a group of heteropteran nymphs escaping from their eggs preserved in Dominican amber. Palaeodiversity 12(1), 123-134. DOI 10.18476/pale.v12.a12

Hsieh, S. \& Plotnick, R.E. 2020. The representation of animal behaviour in the fossil record. Animal Behaviour 169, 65-80. DOI 10.1016/j.anbehav.2020.09.010

Inward, D., Beccaloni, G. \& EgGleton, P. 2007. Death of an order: a comprehensive molecular phylogenetic study confirms that termites are eusocial cockroaches. Biology Letters 3(3), 331-335. DOI 10.1098/rsbl.2007.0102

Jolivet, P., Vasconcellos-Neto, J. \& Weinstein, P. 1990. Cycloalexy: a new concept in the larval defense of insects. Insecta Mundi 394, 133-142.

Karny, H. 1911. Über Thrips-Gallen und Gallen-Thripse. Zentralblatt für Bakteriologie, Parasitenkunde, Infektionskrankheiten und Hygiene, Abteilung II 30, 556-572.

Kerp, H. \& Bomfleur, B. 2011. Photography of plant fossils new techniques, old tricks. Review of Palaeobotany and Palynology 166, 117-151. DOI 10.1016/j.revpalbo.2011.05.001

Kielan-Jaworowska, Z. \& Barsbold, R. 1972. Narrative of the Polish-Mongolian paleontological expeditions, 1967-1971. Palaeontologica Polonica 27, 5-13.

KoČÁReK, P. 2020. A diminutive elcanid from mid-Cretaceous Burmese amber, Ellca nevelka gen. et sp. nov., and the function of metatibial spurs in Elcanidae (Orthoptera). Cretaceous Research 116, art. 104574.

DOI 10.1016/j.cretres.2020.104574

Kramer, J., Thesing, J. \& Meunier, J. 2015. Negative association between parental care and sibling cooperation in earwigs: A new perspective on the early evolution of family life? Journal of Evolutionary Biology 28, 1299-1308. DOI 10.1111/jeb.12655

LAmB, R.J. 1976. Parental behaviour in the Dermaptera with special reference to Forficula auricularia (Dermaptera: Forficulidae). Canadian Entomologist 108, 609-619. DOI 10.4039/Ent108609-6

Latreille, P.A. 1802. Histoire Naturelle des Fourmis et Recueil de Mémoirs et d'Observations sur les Abeilles, les Areignées, les Faucheurs et autres Insectes, Vol. 8. 445 pp. Barrois, Paris. DOI 10.5962/bhl.title.65810

Latreille, P.A. 1804. Tableau méthodique des insectes, 129-200. In Société de Naturalistes et D’Agriculteurs (ed.) Nouveau dictionnaire d'Histoire naturelle 24. Déterville, Paris.

Linnaeus, C. 1758. Systema Naturae per Regna Tria Naturae, Secundum Classes, Ordines, Genera, Species, cum Characteribus, Differentiis, Synonymis, Locis, $10^{\text {th }}$ edition. 824 pp. Laurentius Salvius, Holmiae. DOI 10.5962/bhl.title.542

Liu, X., Zhang, W., Winterton, S.L., Breitkreuz, L.C. \& Engel, M.S. 2016. Early morphological specialization for insectspider associations in Mesozoic lacewings. Current Biology 26, 1590-1594. DOI 10.1016/j.cub.2016.04.039
Liu, X., Shi, G., XiA, F., Lu, X., Wang, B. \& Engel, M.S. 2018. Liverwort mimesis in a Cretaceous lacewing larva. Current Biology 28, 1475-1481. DOI 10.1016/j.cub.2018.03.060

McFarlane, I.E., Steeves, E., Alli, I. 1983. Aggregation of larvae of the house cricket, Acheta domesticus (L.), by propionic acid present in the excreta. Journal of Chemical Ecology 9(9), 1307-1315. DOI 10.1007/BF00994799

Malicky, H. 1984. Ein Beitrag zur Autökologie und Bionomie der aquatischen Netzflüglergattung Neurorthus (Insecta, Neuroptera, Neurorthidae). Archiv für Hydrobiologie 101(1-2), 231-246.

Manica, A., McMeechan, F.K. \& Foster, W.A. 2001. An aggregation pheromone in the intertidal collembolan Anurida maritima. Entomologia experimentalis et applicata 99(3), 393-395. DOI 10.1046/j.1570-7458.2001.00840.x

Mao, Y., Engel, M.S., Ren, D. \& GaO, T. 2020. A new species of Astreptolabis in mid-Cretaceous amber from northern Myanmar, with the discovery of the first male of Astreptolabidinae (Dermaptera). ZooKeys 911, 101-112. DOI 10.3897/zookeys.911.38845

Mas, F. \& Kölliker, M. 2008. Maternal care and offspring begging in social insects: chemical signalling, hormonal regulation and evolution. Animal Behaviour 76(4), 1121-1131. DOI 10.1016/j.anbehav.2008.06.011

MatzKe, D. \& Klass, K.D. 2005. Reproductive biology and nymphal development in the basal earwig Tagalina papua (Insecta: Dermaptera: Pygidicranidae), with a comparison of brood care in Dermaptera and Embioptera. Entomologische Abhandlungen 62(2), 99-116.

MiLler, W. 2007. Trace fossils: concepts, problems, prospects. 611 pp. Elsevier, Amsterdam.

NA, Y., Sun, C., LI, T. \& Li, Y. 2014. The insect oviposition firstly discovered on the Middle Jurassic Ginkgoales leaf from Inner Mongolia, China. Acta Geologica Sinica 88(1), 18-28. DOI 10.1111/1755-6724.12179

NAgEL, M.G. \& CADE, W.H. 1983. On the role of pheromones in aggregation formation in camel crickets, Ceuthophilus secretus (Orthoptera: Gryllacrididae). Canadian Journal of Zoology 61(1), 95-98. DOI 10.1139/z83-010

Nowak, M.A., Tarnita, C.E. \& Wilson, E.O. 2010. The evolution of eusociality. Nature 466(7310), 1057-1062. DOI 10.1038/nature09205

Paterson, J.R., Hughes, N.C. \& Chatterton, B.D., Rábano, I., Gozalo, R., García-Bellido, D. 2008. Trilobite clusters: What do they tell us? A preliminary investigation. Advances in Trilobite Research 9, 313-318.

Peñalver, E. \& Grimaldi, D.A. 2010. Latest occurrences of the Mesozoic family Elcanidae (Insecta: Orthoptera), in Cretaceous amber from Myanmar and Spain. Annales de la Société entomologique de France 46(1-2), 88-99.

DOI 10.1080/00379271.2010.10697641

Pérez-de la Fuente, R., Engel, M.S., Azar, D. \& Peñalver, E. 2019. The hatching mechanism of 130 -million-year-old insects: an association of neonates, egg shells and egg bursters in Lebanese amber. Palaeontology 62(4), 547-559. DOI 10.1111/pala.12414

Peris, D., Labandeira, C.C., Barron, E., Delclos, X., Rust, J. \& 
WANG, B. 2020. Generalist pollen-feeding beetles during the mid-Cretaceous. iScience 23(3), art. 100913.

DOI 10.1016/j.isci.2020.100913

Petrulevičius, J.F., Wappler, T., Nel, A. \& Rust, J. 2011. The diversity of Odonata and their endophytic ovipositions from the Upper Oligocene Fossillagerstätte of Rott (Rhineland, Germany). ZooKeys 130, 67-89. DOI 10.3897/zookeys.130.1441

Pickett, K.M. \& CARPenter, J.M. 2010. Simultaneous analysis and the origin of eusociality in the Vespidae (Insecta: Hymenoptera). Arthropod Systematics and Phylogeny 68(1), 3-33.

Pitman, G.B. \& Vité, J.P. 1969. Aggregation behavior of Dendroctonus ponderosae (Coleoptera: Scolytidae) in response to chemical messengers. The Canadian Entomologist 101(2), 143-149. DOI 10.4039/Ent101143-2

PoInAR, G.O., JR \& PoInAR, R. 1999. The amber forest: a reconstruction of a vanished World. $239 \mathrm{pp}$. Princeton University Press, Princeton.

Poinar, G.O., Jr, Gorochov, A.V. \& Buckley, R. 2007. Longioculus burmensis, n. gen., n. sp. (Orthoptera: Elcanidae) in Burmese amber. Proceedings of the Entomological Society of Washington 109(3), 649-655.

Poinar G.O., JR, Su, Y.N. \& Brown, A.E. 2020. A new genus of crickets (Orthoptera: Gryllidae) in mid-Cretaceous Myanmar amber. Biosis: Biological Systems 1(01), 33-38.

DOI 10.37819/biosis.001.01.0049

Pott, C., Labandeira, C.C., Krings, M. \& Kerp, H. 2008. Fossil insect eggs and ovipositional damage on bennettitalean leaf cuticles from the Carnian (Upper Triassic) of Austria. Journal of Paleontology 82(4), 778-789. DOI /10.1666/06-094.1

Purrington, F.F., Kendall, P.A., Bater, J.E. \& Stinner, B.R. 1991. Alarm pheromone in a gregarious poduromorph collembolan (Collembola: Hypogastruridae). The Great Lakes Entomologist 24(2), 75-78.

Ren, M., Zhang, W., Shin, C. \& Ren, D. 2017. A new earwig (Dermaptera: Pygidicranidae) from the Upper Cretaceous Myanmar amber. Cretaceous Research 74, 137-141. DOI 10.1016/j.cretres.2017.02.012

Ren, M., Zhang, W., Shin, C. \& Ren, D. 2018. Earwig nymphs (Dermaptera) from the mid-Cretaceous amber of Myanmar. Cretaceous Research 90, 382-390.

DOI 10.1016/j.cretres.2018.06.010

Ross, A.J. 2020. Burmese (Myanmar) amber taxa, on-line supplement v. 2020.1, 1-25. https://www.nms.ac.uk/medial 1161742/burmese-amber-taxa-v2020_1.pdf

Ross, A.J. 2021. Burmese (Myanmar) amber taxa, on-line supplement v.2021.1, 1-27. https://www.nms.ac.uk/ media/1164144/burmese-amber-taxa-v2021_1.pdf

Ross, K.G. \& Matthews, R.W. 1989. New evidence for eusociality in the sphecid wasp Microstigmus comes. Animal Behaviour 38(4), 613-619. DOI 10.1016/S0003-3472(89)80006-5

Rust, J., Stumpner, A. \& Gottwald, J. 1999. Singing and hearing in a Tertiary bushcricket. Nature 399(6737), art. 650 . DOI 10.1038/21356

Salmon, S. \& Ponge, J.F. 2001. Earthworm excreta attract soil springtails: laboratory experiments on Heteromurus nitidus (Collembola: Entomobryidae). Soil Biology and Biochemistry 33(14), 1959-1969. DOI 10.1016/S0038-0717(01)00129-8

Salmon, S., Rebuffat, S., Prado, S., Sablier, M., Haese, C. D', Sun, J.S. \& Ponge, J.F. 2019. Chemical communication in springtails: a review of facts and perspectives. Biology and Fertility of Soils 55(5), 425-438.

DOI 10.1007/s00374-019-01365-8

SÁnchez-García, A. \& Engel, M.S. 2016. Springtails from the Early Cretaceous amber of Spain (Collembola: Entomobryomorpha), with an annotated checklist of fossil Collembola. American Museum Novitates 2016(3862), 1-47.

DOI 10.1206/3862.1

Sánchez-García, A., Peñalver, E., Delclòs, X. \& Engel, M.S. 2018. Mating and aggregative behaviors among basal hexapods in the Early Cretaceous. PloS One 13(2), art. e0191669. DOI 10.1371/journal.pone.0191669

Santiago-Blay, J.A., Jolivet, P. \& Verma, K.K. 2012. A natural history of conspecific aggregations in terrestrial arthropods, with emphasis on cycloalexy in leaf beetles (Coleoptera: Chrysomelidae). Terrestrial Arthropod Reviews 5(3-4), 289-355. DOI 10.1163/18749836-05031054

Sarzetti, L.C., Labandeira, C.C., Muzón, J., Wilf, P., Cúneo, N.R., Johnson, K.R. \& Genise, J.F. 2009. Odonatan endophytic oviposition from the Eocene of Patagonia: the ichnogenus Paleoovoidus and implications for behavioural stasis. Journal of Paleontology 83(3), 431-447. DOI 10.1666/08-121.1

Sauphanor, B. \& Sureau, F. 1993. Aggregation behaviour and interspecific relationships in Dermaptera. Oecologia 96(3), 360-364. DOI 10.1007/BF00317506

SchÄdel, M., Hörnig, M.K., HYŽNÝ, M. \& Haug, J.T. 2021. Mass occurrence of small isopodan crustaceans in 100-millionyear-old amber: an extraordinary view on behaviour of extinct organisms. PalZ 95, 429-445. DOI 10.1007/s12542-021-00564-9

Schultz, T.R., Engel, M.S. \& Aschier, J.S. 2001. Evidence for the origin of eusociality in the corbiculate bees (Hymenoptera: Apidae). Journal of the Kansas Entomological Society 74, $10-16$.

SEeley, T.D. 2009. The wisdom of the hive: the social physiology of honey bee colonies. 318 pp. Harvard University Press, Cambridge. DOI 10.2307/j.ctv1kz4h15

Simpson, S.J., Despland, E., Hägele, B.F. \& Dodgson, T. 2001. Gregarious behavior in desert locusts is evoked by touching their back legs. Proceedings of the National Academy of Sciences 98(7), 3895-3897. DOI 10.1073/pnas.071527998

Simpson, S.J., Raubenheimer, D., Behmer, S.T., Whitworth, A. \& Wright, G.A. 2002. A comparison of nutritional regulation in solitarious-and gregarious-phase nymphs of the desert locust Schistocerca gregaria. Journal of Experimental Biology 205(1), 121-129. DOI 10.1242/jeb.205.1.121

Smith, S.M., Beattie, A.J., Kent, D.S. \& Stow, A.J. 2009. Ploidy of the eusocial beetle Austroplatypus incompertus (Schedl) (Coleoptera, Curculionidae) and implications for the evolution of eusociality. Insectes Sociaux 56(3), 285-288. DOI 10.1007/s00040-009-0022-4 
Stern, D.L. \& Foster, W.A. 1996. The evolution of soldiers in aphids. Biological Reviews 71(1), 27-79.

DOI 10.1111/j.1469-185X.1996.tb00741.x

Szinwelski, N., Rosa, C.S., Castro Solar, R.R. de \& Sperber, C.F. 2015. Aggregation of cricket activity in response to resource addition increases local diversity. PloS One 10(10), art. e0139669. DOI 10.1371/journal.pone.0139669

Tallamy, D.W. 1984. Insect parental care. BioScience 34(1), 20-24. DOI 10.2307/1309421

Tallamy, D.W. \& Wood, T.K. 1986. Convergence patterns in subsocial insects. Annual Review of Entomology 31(1), 369-390. DOI 10.1146/annurev.en.31.010186.002101

Thorne, B.L. 1997. Evolution of eusociality in termites. Annual Review of Ecology and Systematics 28(1), 27-54.

DOI 10.1146/annurev.ecolsys.28.1.27

Tillyard, R.J. 1926. The Insects of Australia and New Zealand. 560 pp. Angus \& Robertson, Sydney.

USHER, M.B. 1969. Some properties of the aggregations of soil arthropods: Collembola. Journal of Animal Ecology 38, 607-622. DOI 10.2307/3038

Verhoef, H.A. \& Nagelkerke, C.J. 1977. Formation and ecological significance of aggregations in Collembola. Oecologia 31(2), 215-226. DOI 10.1007/BF00346922

Wang, B., Rust, J., Engel, M.S., Szwedo, J., Dutta, S., Nel, A., Fan, Y., Meng, F., Shi, G., Jarzembowski, E.A., Wappler, T., Stebner, F., FAng, Y., MaO, L., Zheng, D. \& Zhang, H. 2014. A diverse paleobiota in Early Eocene Fushun amber from China. Current Biology 24(14), 1606-1610. DOI 10.1016/j.cub.2014.05.048

Wang, B., Xia, F., Wappler, T., Simon, E., Zhang, H., JarzemBowski, E.A. \& Szwedo, J. 2015. Brood care in a 100-millionyear-old scale insect. eLife 4, art. e05447. DOI 10.7554/eLife.05447

Wang, B., Xia, F., Engel, M.S., Perrichot, V., Shi, G., Zhang, H., Chen J., Jarzembowski E.A, Wappler, T. \& Rust, J. 2016.
Debris-carrying camouflage among diverse lineages of Cretaceous insects. Science Advances 2(6), art. e1501918.

DOI 10.1126/sciadv. 1501918

Wappler, T., Guilbert, E., Labandeira, C.C., HörnscheMEYer, T. \& Wedmann, S. 2015. Morphological and behavioral convergence in extinct and extant bugs: the systematics and biology of a new unusual fossil lace bug from the Eocene. PloS One 10(8), art. e0133330.

DOI 10.1371/journal.pone.0133330

W ATLER, D. 1982. Influence of social situation on food consumption and growth in nymphs of the house cricket, Acheta domesticus. Physiological Entomology 7(3), 343-350.

DOI 10.1111/j.1365-3032.1982.tb00307.x

Wedmann, S., Bradler, S. \& Rust, J. 2007. The first fossil leaf insect: 47 million years of specialized cryptic morphology and behavior. Proceedings of the National Academy of Sciences 104(2), 565- 569. DOI 10.1073/pnas.0606937104

Westwood, J.O. 1888. I. Notes on the life-history of various species of the Neuropterous genus Ascalaphus. Transactions of the Royal Entomological Society of London 36(1), 1-12. DOI 10.1111/j.1365-2311.1888.tb00654.x

Wichard, W., Gröhn, C. \& Seredszus, F. 2009. Aquatic insects in Baltic amber. 336 pp. Remagen, Kessel.

Wilson, E.O. \& HöLldobler, B. 2005. Eusociality: origin and consequences. Proceedings of the National Academy of Sciences 102(38), 13367-13371. DOI 10.1073/pnas.0505858102

WitMER, L.M. 1995. The extant phylogenetic bracket and the importance of reconstructing soft tissues in fossils. Functional Morphology in Vertebrate Paleontology 1, 19-33.

Yoder, J.A., Hobbs III, H.H. \& Hazelton, M.C. 2002. Aggregate protection against dehydration in adult females of the cave cricket, Hadenoecus cumberlandicus (Orthoptera, Rhaphidophoridae). Journal of Cave and Karst Studies 64(2), 140-144. 